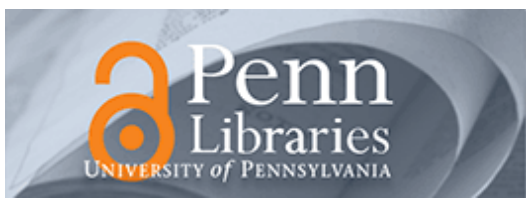

University of Pennsylvania ScholarlyCommons

Wharton Pension Research Council Working Papers

Wharton Pension Research Council

$4-1-2010$

\title{
Optimal Portfolio Choice over the Life Cycle with Social Security
}

Kent A. Smetters

The Wharton School, University of Pennsylvania, smetters@wharton.upenn.edu

Ying Chen

The Wharton School, University of Pennsylvania, yingcn@wharton.upenn.edu

Follow this and additional works at: https://repository.upenn.edu/prc_papers

Part of the Economics Commons

Smetters, Kent A. and Chen, Ying, "Optimal Portfolio Choice over the Life Cycle with Social Security" (2010). Wharton Pension Research Council Working Papers. 192.

https://repository.upenn.edu/prc_papers/192

This paper is posted at ScholarlyCommons. https://repository.upenn.edu/prc_papers/192

For more information, please contact repository@pobox.upenn.edu. 


\title{
Optimal Portfolio Choice over the Life Cycle with Social Security
}

\begin{abstract}
This paper examines how households should optimally allocate their portfolio choices between risky stocks and risk-free bonds over their lifetime. Traditional lifecycle models in previous work suggest that the allocation toward stocks should start high (near 100\%) early in life and decline over a person's age as human capital depreciates. These models also suggest that, with homothetic utility, the allocation should be roughly independent of a household's permanent income. The actual empirical evidence, however, indicates more of a "hump" shape allocation over the lifecycle; the lifetime poor also hold a smaller percentage of their portfolio in stocks relative to higher income groups. Households, therefore, appear to be making considerable "mistakes" in their portfolio allocation. Target date funds, which have grown enormously during the past five years, aim to simplify the investment process in a manner consistent with the predictions of this traditional model. We reconsider the portfolio choice allocation in a computationally-demanding lifecycle model in which households face uninsurable wage shocks, uncertain lifetime as well as a progressive and wage-indexed social security system. Social security benefits, therefore, are correlated with stock returns at a low frequency that is more relevant for lifecycle retirement planning. We show that this model is able to more closely replicate the key stylized facts of portfolio choice. In fact, when calibrated to the age-based income-wealth ratios found in the Survey of Consumer Finances, we demonstrate that the portfolio allocation "mistakes" being made by the vast majority of households actually lead to larger levels of welfare relative to the traditional advice incorporated in target date funds.
\end{abstract}

\section{Keywords}

Portfolio, Social Security, Income, Model, Retirement, Households, Wages, Lifecycle, Wealth, Allocation, Stocks, Correlation, Model

\section{Disciplines}

Economics 


\title{
Optimal Portfolio Choice over the Life Cycle with Social Security
}

Kent A. Smetters and Ying Chen

April 2010

\author{
PRC WP2010-06 \\ Pension Research Council Working Paper \\ Pension Research Council \\ The Wharton School, University of Pennsylvania \\ 3620 Locust Walk, 3000 SH-DH \\ Philadelphia, PA 19104-6302
}

Tel: 215.898.7620 Fax: 215.573.3418

Email: prc@wharton.upenn.edu

http://www.pensionresearchcouncil.org

Opinions and conclusions are solely those of the author(s) and do not reflect views of the institutions supporting the research, with whom the authors are affiliated, or the Pension Research Council. Copyright 2010 (C) Pension Research Council of the Wharton School of the University of Pennsylvania. All rights reserved. 


\title{
Optimal Portfolio Choice over the Life Cycle with Social Security
}

\author{
Kent A. Smetters and Ying Chen
}

This paper examines how households should optimally allocate their portfolio choices between risky stocks and risk-free bonds over their lifetime. Traditional lifecycle models in previous work suggest that the allocation toward stocks should start high (near 100\%) early in life and decline over a person's age as human capital depreciates. These models also suggest that, with homothetic utility, the allocation should be roughly independent of a household's permanent income. The actual empirical evidence, however, indicates more of a "hump" shape allocation over the lifecycle; the lifetime poor also hold a smaller percentage of their portfolio in stocks relative to higher income groups. Households, therefore, appear to be making considerable "mistakes" in their portfolio allocation. Target date funds, which have grown enormously during the past five years, aim to simplify the investment process in a manner consistent with the predictions of this traditional model. We reconsider the portfolio choice allocation in a computationally-demanding lifecycle model in which households face uninsurable wage shocks, uncertain lifetime as well as a progressive and wage-indexed social security system. Social security benefits, therefore, are correlated with stock returns at a low frequency that is more relevant for lifecycle retirement planning. We show that this model is able to more closely replicate the key stylized facts of portfolio choice. In fact, when calibrated to the age-based income-wealth ratios found in the Survey of Consumer Finances, we demonstrate that the portfolio allocation "mistakes" being made by the vast majority of households actually lead to larger levels of welfare relative to the traditional advice incorporated in target date funds. 


\section{Introduction}

A considerable literature has examined how households should optimally allocate their savings between stocks and bonds over their lifecycle. Samuelson (1969) and Merton (1969) first addressed this problem in discrete and continuous time, respectively, assuming complete markets without labor income. Merton (1971) then introduced deterministic labor income into the continuous time framework while Bodie, Merton and Samuelson (1992) allowed for it to be elastically supplied. In more recent years, attention has shifted toward examining how uninsurable labor income risk and uncertain lifespans impact savings and portfolio allocations over the life cycle. ${ }^{1}$

It is well known, however, that the standard expected-utility model does not appear to closely match the empirical evidence on portfolio choice. ${ }^{2}$ The actual empirical evidence suggests three "stylized facts:” (I) the share of a household's portfolio invested in equities is much less than $100 \%$ for most households; (II) the lifetime poor invest in fewer equities than richer households; and (III) the share of portfolio invested in risky assets tend to be "hump shape” ( $\cap$ ) in age.(Ameriks and Zeldes 2000; Heaton and Lucas 2000; Poterba and Samwick, 2002).In contrast, the standard model with homothetic preferences tends to generate a very high stock allocation across all income classes (near 100\%) that declines with age as human capital depreciates; in many portfolio choice models, the allocation is counterfactually " $U$ shaped" in age.

Several modifications to the standard model have been proposed in the past to deal with at least one of these empirical observations: liquidity constraints (Brown 1990; Ameriks and Zeldes 2000); saving for illiquid assets such as a house (Faig and Shum 2002); habit persistence (Polkovnichenko, 2007); and, incomplete trading markets between generations in a real business cycle economy where wages and stock returns are perfectly correlated

\footnotetext{
${ }^{1}$ See Bertaut and Haliassos (1997); Gakidis (1998); Storesletten, Telmer, and Yaron (2000, 2007); Viceira (2001); Bodie, Detemple, and Walter (2004); Benzoni, Collin-Dufresne and Goldstein (2004); Cocco, Gomes and Maenhout (2005) and Gomes and Michaelides (2005). Related papers by Balduzzi and Lynch (1997), Brennan and Xia (1998), Campbell and Viceira (1999), and Kim and Omberg (1996) study the effects caused by the changes of riskfree interest rate or equity premium over the time. Carroll (2002) and Campbell and Cochrane (1999) propose models in which risk aversion varies with wealth.

${ }^{2}$ Of course, a plausible model should also match key stylized facts regarding consumption profiles and wealthincome ratios over the lifecycle, which we discuss later. Previous models, however, have been more successful at generating these features.
} 
(Storesletten, Telmer, and Yaron, 2007). In contrast, the current paper preserves the standard lifecycle expected utility model with homothetic utility but simply considers the importance of a more detailed fiscal setting: a wage-indexed and progressive social security system.

In the United States, a retiree's initial Social Security benefit level is calculated by first multiplying each previous wage earned by the participant with a wage-indexed factor. This factor tracks the average wage growth experienced across the entire economy since the time that particular wage was earned. For example, suppose that you retired today and you earned $\$ 30,000$ twenty years ago. Also suppose that wages, averaged across the entire economy, grew on average of 5\% (nominal) per year during the past 20 years. Your recorded wage of $\$ 30,000$ would, therefore, be adjusted upward by a factor of $1.05^{20}=2.65$, or equal $\$ 79,598.93$. A similarly constructed wage factor would be applied to each of your other previous wages as well. Your individual Average Indexed Yearly Earnings (AIYE) would then be determined by taking the average of your adjusted wages. ${ }^{3}$ Progressivity is then introduced by calculating your Primary Insurance Amount (PIA) using a nonlinear (progressive) function of your AIYE. Your PIA forms the basis of your Social Security benefit amount before some additional adjustments are made (e.g., a spousal benefit). ${ }^{4}$

Empirically, in the United States, Social Security wage index factors that are used to adjust previous earnings are highly correlated with stock returns. At first glance, this fact might be surprising since it is well known that average wages and stock returns are not highly correlated at "high" (annual) frequency even at the sectorial level (e.g., Davis and Paul 2000). However, there are two distinct differences. First, "idiosyncratic" (including sectorspecific) risks tend to cancel inside of the economy-wide average index wage factor that is used to adjust previous wages for calculating U.S. Social Security benefits. Second, and more importantly, this indexation is calculated at a "low frequency," especially for previous wages earned early in the lifecycle. The economy-wide average wage and stock returns are

\footnotetext{
${ }^{3}$ Technically speaking, in the United States, this calculation is done at monthly (not yearly) frequency to calculuate the Average Indexed Monthly Earnings (AIME). Moreover, only the best "best 35" years of earnings - those with the larged adjusted wages - are included in the AIME. We ignore these finer details in order to keep the state space more manageable. The U.S. system also has a cap on yearly wages subject to the payroll tax, and the AIME is, therefore, calculated over capped wages. Our calculations include this cap.

${ }^{4}$ Individuals with a larger AIYE receive a larger PIA, thereby recognizing that they paid more into the system. However, the PIA / AIYE ratio - the "replacement rate" - is a declining function of the AIYE so that the lifetime poor receives a relatively larger replacement rate of their previous earnings.
} 
much more highly correlated at this lower frequency (Jermann, 1999). ${ }^{5}$

Wage indexation has not been considered in the previous literature, and its inclusion adds considerable computational complexity. We show, however, that a wage-indexed social security system can potentially play an important role in reconciling all three stylized facts noted above. First, a wage-indexed social security system provides a retirement asset that is highly correlated with stock returns, thereby reducing the demand for stocks by most households (stylized fact (I)). Second, this effect is especially strong for lower-income households who derive most of their retirement income from social security due to its progressive benefit structure (stylized fact (II)). For poor households (many of whom don't have access to employer-based defined-contribution retirement plans), we also investigate how a realistic minimum investment account requirement in stocks reinforces the pattern observed in our model. Third, the correlation between social security and equity returns is larger at younger ages, reducing the demand for equity. As benefits begin to accrue at higher ages and the horizon toward retirement becomes shorter, social security benefits begin to become more substitutable with bonds, thereby increasing the demand for equities. Closer to retirement, enough human capital has depreciated, making stocks less attractive again (stylized fact (III)).

One might object to our positive findings by arguing that few people actually understand the complexities of how their social security benefits are calculated. We tend to agree. Unlike positive analysis, we have not made a substantial effort to "rig" our model to produce the observable pattern of portfolio allocation over the lifecycle. Instead, our results, like many previous analyses, are likely best interpreted as normative. We simply calibrate our model to generate the observable wealth-income ratio across the lifecycle by education class, and we report the corresponding portfolio allocation. For some parameter sets, our simulated post-retirement asset portfolios, however, sometimes diverges from the empirical data: the optimal portfolio actually reverses direction (creating a "M" like shape) as social security, which is a safe annuity, becomes a larger fraction of post-retirement wealth. These results suggest that traditional portfolio advice - suggesting that young people hold lots of equities while the old hold fewer - might be completely wrong on both sides of the age spectrum.

\footnotetext{
${ }^{5}$ This result is consistent with a neoclassical model with shocks to productivity and depreciation.
} 
Our model indicates that younger people should devote a smaller percentage of their wealth to equities while, in many cases, retirees should actually increase their equity holdings postretirement.

Just how off the mark is traditional portfolio advice? To be sure, relative to our model, any advice that is not consistent with our model would, by definition, appear to be inferior. So, instead, we ask a bolder question that is testable: are households potentially better off with their current observable portfolio allocations relative to the lifecycle allocation that is recommended by the traditional lifecycle model without wage-indexed social security? This comparison is particularly important in light of the enormous growth during the past five years in so-called "target date” mutual funds that automatically rebalance a household's investment according to the allocation suggested by traditional lifecycle models. Our results suggest that observable current household behavior actually produces a larger welfare than the allocations created by target date funds.

\section{Empirical Evidence}

It's helpful to first start with an overview of the actual decisionmaking of households. The Survey of Consumer Finances (SCF) is generally considered the best data source for reporting the financial wealth of U.S. families. It provides comprehensive coverage of different measures of wealth as well as key characteristics (age, education, etc.) that tend to be correlated with wealth. The SCF is conducted every three years with different families; we report evidence from the most recent sample from the year 2004. ${ }^{6}$ However, as Ameriks and Zeldes (2000) warn, the exact magnitude of these estimates should be taken with a "grain of salt" due to data definitions and other issues. Appendix A describes the definitions and variables from SCF 2004 that we use in our empirical estimation.

Figure 1 reports the average (mean) percent of a household's portfolio invested in risky stocks by age for families in which the "household head" (primary earner) falls into one of three different education groups: "No High School" education; with "High School” educa-

\footnotetext{
${ }^{6}$ The SCF is a non-panel data dataset that uses a dual-frame sample design. One part is selected to obtain a sufficiently large and unbiased sample. The other part is designed to disproportionately select wealthier families. We use the provided weights to adjust the unequal probabilities of selection in the survey and for nonresponse.
} 


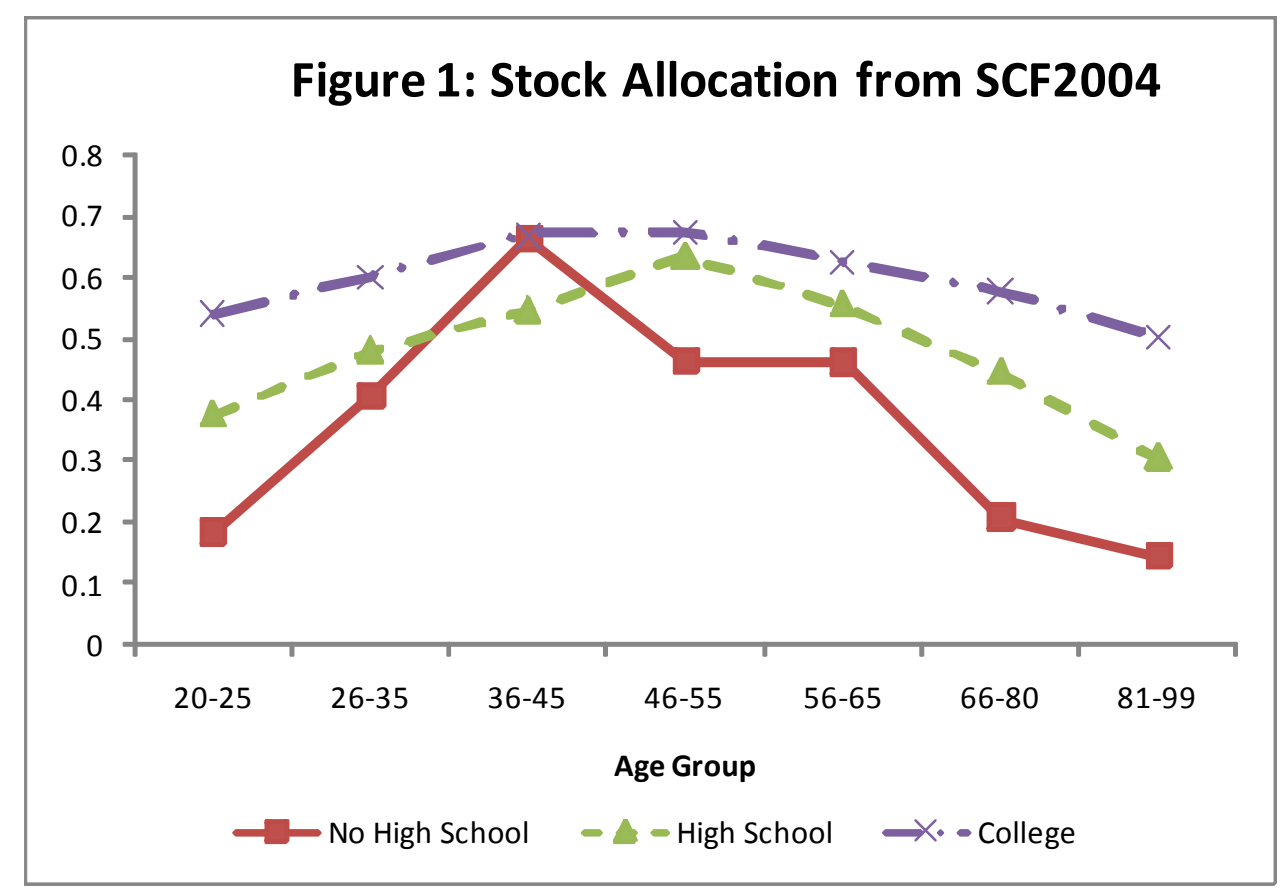

Figure 1:

tion only; with "College” education. Households are grouped into five-year "age buckets” in order to increase the sample size per cell. Figure 1 reveals the three key stylized facts that motivate this paper: (I) the share of a household's portfolio invested in equities is much less than $100 \%$ for most households; (II) the lifetime poor (those with less education) invest in fewer equities than richer households; and (III) the share of portfolio invested in risky assets tend to be "hump shaped” (or "inverse U”) in age.

Figure 2 reports the average of total wealth relative to total (labor) income for these same education groups, respectively. Overall, wealth-income ratios increase with age and education. The age-shape of the accumulation profiles also suggest a significant bequest motive that is increasing in the education class. However, the exact steepness post-retirement should also be taken with a "grain of salt" due to potential survivor bias where wealthier households tend to live longer on average. We calibrate our model using the data presented in Figure 2 and we then report how our simulated portfolio allocations compare with the reuslts shown in Figure 1. This approach reduces our ability to pick the model's deep structural 


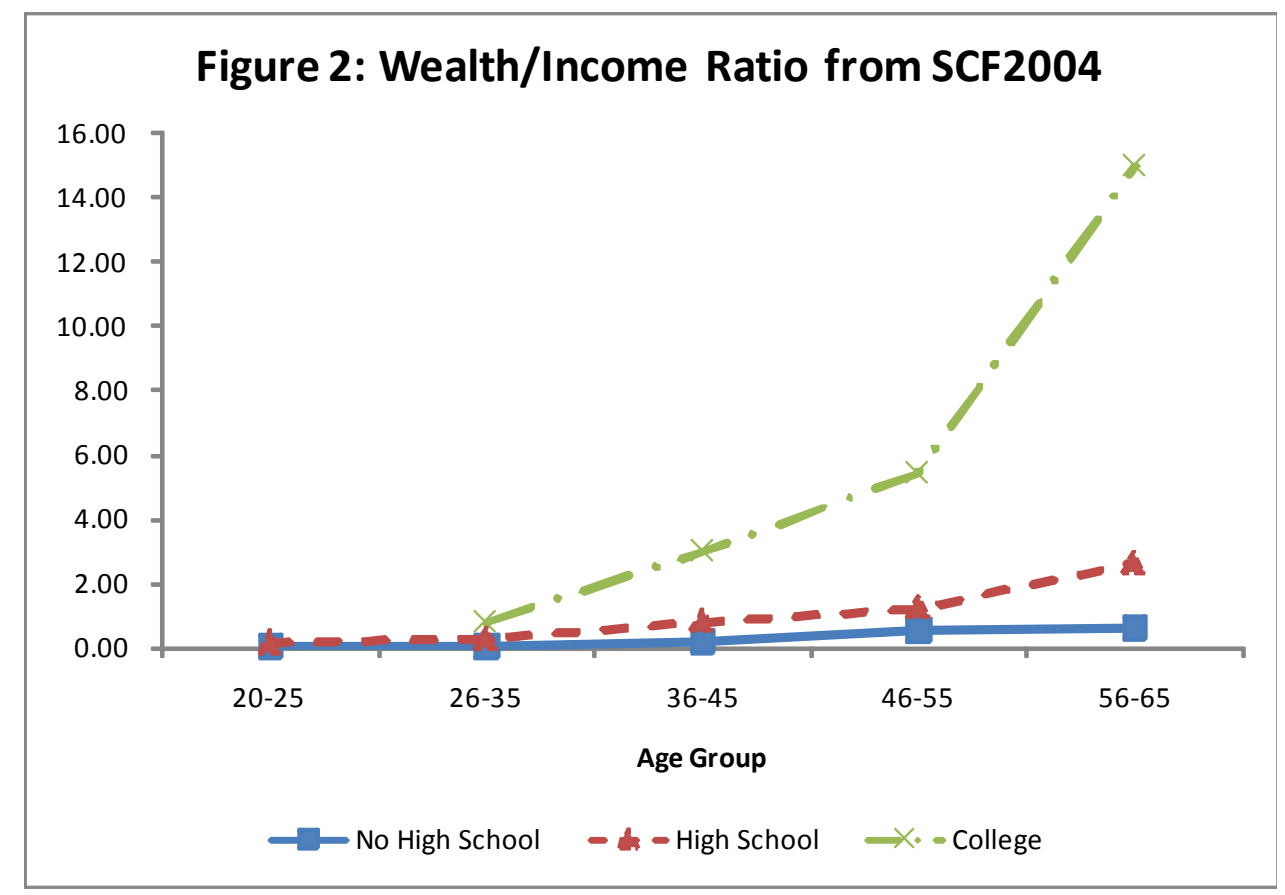

Figure 2:

parameters in order to try to simply match Figure 1; it also means that our simulations are consistent with several aspects of lifecycle optimization rather than just our reported target.

\section{Specification of the Model}

This section presents a lifecycle portfolio choice model with standard preferences where households face uncertain and uninsurable wage earnings as well as an uncertain length of life. ${ }^{7}$ Individuals make their consumption, saving and portfolio decisions over risk-free bonds and risky stocks at the beginning of each period during their working years. Their savings and portfolio choices are motivated by three main factors: to buffer uncertainty in the presence of incomplete insurance markets (precautionary savings); consumption needs after retirement; and, a joy-of-giving desire to leave a bequest. Individuals also pay a social security tax during their working years in exchange for a social security benefit during

\footnotetext{
${ }^{7}$ While wages are typically uninsurable in the private sector, private annuities directly hedge against an uncertain length of life, although these instruments are uncommonly used for this purpose (rather than tax benefits). In our baseline simulations, we assume that households do not annuitize, although our model could be easily solved allowing for perfect annuities.
} 
retirement that augments their private savings.

\subsection{Preferences}

Each individual $i$ works from age $t_{0}$ to retirement age $M$. The maximum length of life is $T$ and $p_{t}$ is the probability that the individual is still alive at age $t+1$ conditional on being alive at age $t$. Preferences take the standard Constant Relative Risk Aversion (CRRA) form and are additively separable over time..The household's maximum expected utility at $t_{0}$, therefore, is

$$
\max E_{t_{0}} \sum_{t=t_{0}}^{T} \beta^{t-t_{0}}\left(\prod_{j=t_{0}-1}^{t-2} p_{j}\right)\left(p_{t-1} \frac{C_{i, t}^{1-\gamma}}{1-\gamma}+b\left(1-p_{t-1}\right) \frac{W_{i, t}^{1-\gamma}}{1-\gamma}\right)
$$

where $\beta<1$ is the weight placed on future utility; $C_{i, t}$ is $i$ 's consumption at age $t$; $\gamma$ is the coefficient of relative risk aversion. $W_{i, t}$ is the wealth (bequest) left at the time of the death where $b$ identifies the intensity of the bequest motive.

\subsection{Financial Assets}

Investors have access to two investment instruments: risk-free bonds and risky stocks. The riskless bonds pay a constant gross real return $R_{f}$, while the risky asset pays a gross real return $R_{t}^{S}$ :

$$
R_{t}^{S}=R^{f}+\mu+\eta_{t}
$$

where $\mu$ is the deterministic equity premium and $\eta_{t}$ is the innovation to this excess returns of time $t . \quad \eta_{t}$ is independently and identically distributed (i.i.d.) over time and normally distributed $N\left(0, \sigma_{\eta}\right)$.

\subsection{Labor Income}

Following Carroll (1997), Gourinchas and Parker (2002), Cocco, Gomes and Maenhout (2005), and several other papers, exogenous labor income for agent $i$ at time $t$ is modeled as

$$
Y_{i, t}=\exp \left(y_{i, t}\right)
$$


Before retirement, log income is composed of three terms:

$$
y_{i, t}=g\left(t, F_{i, t}\right)+\omega_{i, t}+z_{i, t}
$$

where $g\left(t, F_{i, t}\right)$ is a deterministic function of age $t$ and other individualistic characteristics $F_{i, t} ; \omega_{i, t}$ is an (idiosyncratic) i.i.d. normally distributed shock $N\left(0, \sigma_{\omega}\right)$; and, $z_{i, t}$.is a firstorder (permanent) autoregressive shock

$$
z_{i, t}=\theta z_{i, t-1}+\xi_{t}+\phi_{i, t}
$$

with an autocorrelation coefficient equal to $\theta$; and, an aggregate (economy-wide) component $\xi_{t}$ and idiosyncratic component $\phi_{i, t}$ that are distributed i.i.d. as $N\left(0, \sigma_{\xi}\right)$ and $N\left(0, \sigma_{\phi}\right)$, respectively. We also allow the correlation between the innovation to excess stock returns $\eta_{t}$ and the aggregate labor income shock $\xi_{t}$ to equal $\rho_{\xi \eta}$ so that $\eta_{t}$ and $\xi_{t}$ are jointly bivariate distributed (see the Appendix). Assuming rational expectations, while individuals don't know their income and stock returns in the next period, they are aware of the underlying distributions.

Individuals pay a flat social security tax rate of $\tau_{S S}$ through their working years and a nonlinear labor income tax rate $\tau_{w}$ calibrated below. The (net of tax) disposable labor income at time $t$ for individual $i$, therefore, is:

$$
\begin{aligned}
Y_{i, t}^{d} & =\left(1-\tau_{S S}\right)\left(1-\tau_{w}\left[Y_{i, t}\right]\right) Y_{i, t} \text { for } t<M \\
& =0 \text { for } t \geq M
\end{aligned}
$$

\subsection{Wage-Indexed Social Security}

Social security benefits received at the point of retirement at age $M$ are based, in part, on the individual's Average Indexed Yearly Earnings (AIYE) during their working years. The AIYE is calculated by adjusting upward each wage earned by individual $i$ during the previous year $t$ by the growth in the aggregate (economy-wide) average wage between year $t$ and the retirement year, $M$. Denote $Y_{t}^{A}$ as the aggregate average wage level at time $t$. The

appropriate wage index adjustment factor for wages earned in year $t$, therefore, equals $\frac{Y_{M}^{A}}{Y_{t}^{A}}$, which is the cumulative growth in aggregate wages between times $t$ and $M$. Individual $i$ 's 
AIYE at the point of retirement, therefore, is equal to the sum of all previous wages adjusted upward by their respective wage index factors, divided by the number of working years: ${ }^{8}$

$$
\begin{aligned}
\bar{Y}_{i, M} & =\frac{Y_{i, t_{0}} \frac{Y_{M}^{A}}{Y_{t_{0}}^{A}}+Y_{i, t_{0}+1} \frac{Y_{M}^{A}}{Y_{t_{0}+1}^{A}}+\cdots+Y_{i, M-1} \frac{Y_{M}^{A}}{Y_{M-1}^{A}}}{M-t_{0}} \\
& =\frac{\left(\left(Y_{i, t_{0}} \frac{Y_{t_{0}+1}^{A}}{Y_{t_{0}}^{A}}+Y_{i, t_{0}+1}\right) \frac{Y_{t_{0}+2}^{A}}{Y_{t_{0}+1}^{A}}+Y_{i, t_{0}+2}\right) \cdots}{M-t_{0}}
\end{aligned}
$$

The aggregate wage level is modeled as a first-order autoregressive process with a unitroot in logs:

$$
Y_{t+1}^{A}=Y_{t}^{A} \cdot \exp \xi_{t+1}
$$

which we can rewrite as:

$$
\frac{Y_{t+1}^{A}}{Y_{t}^{A}}=\exp \xi_{t+1}
$$

We can then track individual $i$ 's AIYE at each age based on his AIYE in the previous age: ${ }^{9}$

$$
\bar{Y}_{i, t+1}=\frac{\left(t-t_{0}\right) \bar{Y}_{i, t} \cdot \exp \xi_{t+1}+Y_{i, t+1}}{t-t_{0}+1}
$$

Social security benefits at retirement, therefore, are a function of individual $i$ 's AIYE:

$$
\begin{aligned}
S S_{i, t} & =Q\left(\bar{Y}_{i, M}\right) \text { for } t \geq M \\
& =0 \text { for } t<M
\end{aligned}
$$

where $Q()$ is a nonlinear function calibrated to the U.S. Social Security system (discussed below).

\footnotetext{
${ }^{8}$ Technically, in the United States, only the "best 35 years" are actually counted in the computation of the average wage. Tracking that decomposition, however, would require several more state variables, and would not materially alter our conclusions.

${ }^{9}$ This "rolling average" approach allows us to track the individual's AWIE with the additional of just one state variable.
} 
The correlation between the aggregate average wage and stock returns, therefore, is $\rho_{\xi \eta}=\frac{\operatorname{cov}\left(\xi_{t}, \eta_{t}\right)}{\sigma_{\xi} \cdot \sigma_{\eta}}$. However, the correlation between individual $i$ 's (log) wage and stock returns is approximately one-fourth of the size due to additional idiosyncratic risk that is present in the individuals wage:

$$
\rho_{y \eta}=\frac{\operatorname{cov}\left(\xi_{t}, \eta_{t}\right)}{\sigma_{\eta} \cdot \sqrt{\sigma_{\xi}^{2}+\sigma_{\phi}^{2}+\sigma_{\omega}^{2}}} \approx \frac{\operatorname{cov}\left(\xi_{t}, \eta_{t}\right)}{\sigma_{\eta} \cdot \sqrt{16 \cdot \sigma_{\omega}^{2}}}=\frac{\operatorname{cov}\left(\xi_{t}, \eta_{t}\right)}{4 \cdot \sigma_{\xi} \cdot \sigma_{\eta}}
$$

The distinction between these correlations allows us to increase the aggregate average wage correlation with stocks (without the idiosyncratic terms) to a larger generational-level frequency value while preserving a much smaller correlation value that households individually face at high frequency (with idiosyncratic terms). ${ }^{10}$

\subsection{Optimization Problem}

As in several previous papers, we treat the share of income spent on housing, $h_{t}$, as an "above-the-line” expense that exogenously reduces pre-retirement disposable income. In each period $t$, individual $i$ has "cash on hand" denoted as $X_{i, t}$, which is composed of the following resources: wealth $W_{i, t}$ at the beginning of each period (which is equal to the bequest in the case of death); plus, disposable income net of housing expenditures received before retirement; plus, social security benefits (after retirement):

$$
X_{i, t}=W_{i, t}+\left(1-h_{t}\right) Y_{i, t}^{d}+S S_{i, t}
$$

Given the cash on hand at time $t$, individual $i$ then jointly decides how much to consume $C_{i, t}$ and the share of the residual savings, $X_{i, t}-C_{i, t}$, that is invested into risky equities versus risk-free bonds. Denote $\alpha_{i, t}$ as the proportion invested into the risky asset; hence, $1-\alpha_{i, t}$ is the share invested into risk-free bonds. We assume $\alpha_{i, t} \in[0,1]$, so that the allocation into bonds and stocks has to be positive at any period; in our actual simulations, these constraints

\footnotetext{
${ }^{10}$ To be sure, the aggregate average wage correlation with stocks will also be large even at a high frequency under this approach. (Distinguishing explicitly between low and high frequency values for the aggregate correlation would require additional state variables.) However, individual households never observe this particular correlation. Instead, they only see the high-frequency small correlation with their own wages and the low-frequency large correlation through eventual wage indexation of their future social security benefits.
} 
are not binding. ${ }^{11}$

For calibration purposes, we allow the investment return to be taxed at a rate $\tau_{d}$. $R_{i, t}$ denotes the total gross real return on the portfolio at time $t$. When the net stock return is positive $R_{i, t}^{S}>1$, the investor is taxed on both asset classes; otherwise, only the risk-free asset is taxed: ${ }^{12}$

$$
\begin{aligned}
R_{i, t} & =\left[\alpha_{i, t} \cdot R_{i, t}^{S}+\left(1-\alpha_{i, t}\right) \cdot R_{f}-1\right] \cdot\left(1-\tau_{d}\right)+1 \text { for } R_{i, t}^{S}>1 \\
& =\alpha_{i, t} \cdot R_{i, t}^{S}+\left(1-\alpha_{i, t}\right) \cdot\left[\left(R_{f}-1\right) \cdot\left(1-\tau_{d}\right)+1\right] \text { for } R_{i, t}^{S} \leq 1
\end{aligned}
$$

The amount of wealth the following period, $t+1$, therefore, equals

$$
W_{i, t+1}=R_{i, t}\left(X_{i, t}-C_{i, t}\right)
$$

The model, therefore, has four state variables, $\left\{t, X_{i, t}, z_{i, t}, \bar{Y}_{i, t+1}\right\}$, along with two timevectored control variables: $\left\{C_{i, t}, \alpha_{i, t}\right\}_{t=t_{0}}^{T}{ }^{13}$ In some of our simulations, we also require the total amount of saving invested into the risky asset, $\alpha_{i, t}\left(X_{i, t}-C_{i, t}\right)$ to exceed a minimum threshold $m$ in each period of life. This requirement is especially relevant for households without access to employer-based defined-contribution plans. Thus, in general, individual $i$ 's maximization problem can be restated recursively as follows

$V_{i, t}\left(X_{i, t}, z_{i, t}\right)=\max _{C_{i, t}, \alpha_{i, t}}\left\{\frac{\left(C_{i, t}\right)^{1-\gamma}}{1-\gamma}+\beta E_{t}\left[p_{t} \cdot V_{i, t+1}\left(X_{i, t+1}, z_{i, t+1}\right)+b\left(1-p_{t}\right) \cdot\left(\frac{\left(W_{i, t+1}\right)^{1-\gamma}}{1-\gamma}\right)\right]\right\}$

\footnotetext{
${ }^{11}$ Intuitively, a short position in equities $(\alpha<0)$ would expose agent $i$ to potentially unbounded losses, a risk that would never be taken under the Inada conditions satisfied by CRRA utility. However, a short position in bonds $(\alpha>1)$ is certainly plausible with a low CRRA parameter $\gamma$ and a large equity premium $\eta$ if the present value of "safe" future labor income (the deterministic component minus the upper support on the risky components) is large enough. This outcome has occurred in some previous papers but does not appear herein under our calibrations and modeling of social security.

${ }^{12}$ Thus, we take a somewhat conservative view on the value of carry forward provisions for loss offsets available in US tax law.

${ }^{13}$ Our state space, therefore, is about 100 times larger than most existing portfolio choice models due to our added complexities. Despite our choice of homothetic utility, our model is not homogenous of degree 1 due to the presence of nonlinear fiscal policies. We, therefore, cannot employ the standard technique of dropping the current state of income. We must also track the household's average wage.
} 
subject to ${ }^{14}$

$$
\begin{aligned}
& \alpha_{i, t} \in[0,1] \\
& X_{i, t+1}=R_{i, t}\left(X_{i, t}-C_{i, t}\right)+\left(1-h_{t+1}\right) Y_{i, t+1}^{d}+S S_{i, t} \\
& 0 \leq \alpha_{i, t}\left(X_{i, t}-C_{i, t}\right) \notin(0, m)
\end{aligned}
$$

where $m \geq 0$ is set exogenously.

\subsection{Numerical Solution}

This maximization problem cannot be solved analytically. So numerical dynamic programming methods are used. While discussions of numerical methods are often relegated to technical appendices, special attention must be paid to methodology used in our model, due to the constraints and need to preserve shape of the value function. Indeed, the vast majority of our effort was spent on investigating a large range of different numerical algorithms in order to produce verifiable and accurate results.

The model is solved using backward iteration over the time dimension in order to derive the policy functions $C_{i, t}\left(X_{i, t}, z_{i, t}, \bar{Y}_{i, t+1}\right)$ and $\alpha_{i, t}\left(X_{i, t}, z_{i, t}, \bar{Y}_{i, t+1}\right)$.The continuous state space is approximated using a power-spaced discrete grid. The value of the function $V_{i, t+1}$ must be approximated between grid points across the three non-time dimensions: Schumaker shape-preserving quadratic splines are used inside the state variable exhibiting the most curvature (cash-on-hand) along with bilinear interpolation inside the other two dimensions. ${ }^{15}$ There exist three labor income shocks $\left(\omega_{i, t}, \xi_{t}\right.$ and $\left.\phi_{i, t}\right)$ as well as uncertainty to the innovation of excess stock returns $\eta_{t}$. Gauss-Hermite quadrature is used to discretize these

\footnotetext{
${ }^{14}$ The additional constraint, $C_{i, t}>0$, never binds in our model under the Inada conditions consistent with CRRA utility.

We also formally require that total savings at time $t$ be positive (i.e., $\left(X_{i, t}-C_{i, t}\right)>0$ ) to prevent any attempt to borrow against the "safe" portion of future labor income or social security benefits. Theoretically, this constraint should also never bind under the Inada conditions since, under our distributional assumptions, the individual $i$ 's labor income in any year could be zero, as could the aggregate wage index factor. (In other words, there is actually no positive levels of "safe" labor or social security income.) In actual simulations, however, both of these terms must be bounded above zero when using standard numerical integration approximation methods. Still, the minimum integrated node is small enough to prevent negative savings.

${ }^{15}$ We thanks Ken Judd for this suggestion. Consistent with suggestions in Judd (1998), we found several other approximation methods to be very inaccurate, including Chebyshev polynomials. Schumaker splines does not generalize easily to more than one dimension.
} 
shocks into several nodes for the numerical integration that is required to compute expectations. However, since the innovations to stock returns are assumed to be correlated with an aggregate permanent income shock, a transformation to the Gauss-Hermite quadrature is required in order to implement the bivariate normal distribution, as shown in Appendix B. Maximization at each grid point is performed using a combination of simplex optimization (the Nelder-Mead method) and Brent's method (when feasible). While slower than gradientbased methods, they are more reliable. ${ }^{16}$

Correctly imposing the minimum threshold constraint (17) requires some care. The optimization problem is first solved (using simplex optimization) at the given grid point without the constraint (17) imposed. If the constraint (17) is not violated then that solution is obviously used. Otherwise, two additional conditional optimization problems are solved (now using Brent's method): where $\alpha_{i, t}\left(X_{i, t}-C_{i, t}\right)=0$ and where $\alpha_{i, t}\left(X_{i, t}-C_{i, t}\right)=m$. The best solution (highest value function) of those two optimizations is then chosen, which under our convexity assumptions, must be be larger than any interior point where $\alpha_{i, t}\left(X_{i, t}-C_{i, t}\right)>m$. Solving individual $i$ 's lifetime maximization problem, therefore, requires up to $600,000,000$ optimization subproblems to be solved, which requires about 250 CPU hours using a highend processor and FORTRAN 90. ${ }^{17}$ The simulation is solved with FORTRAN 90 MPI using a grid network where parallelization is conducted along the age (time) dimension.

However, to prevent us from simply picking parameter combinations that attempt to produce the empirical stock allocation over the lifecycle, we instead calibrate our model to produce the empirically observable wealth-to-income ratios over the lifecycle (Figure 2). This overidentifying restriction effectively creates an additional “outer loop” that requires testing many additional cases. Because each simulation, though, is very costly to compute, we instead manually "hunt and peck" at these parameters to generate wealth-income ratios that are “close enough” (as reported below).

Following Judd (1992, 1998), the accuracy of any simulation is likely best judged from

\footnotetext{
${ }^{16}$ Several other maximization methods and approaches were examined, including derivative-based methods as well as state-of-the-art quasi-Newton methods modified to ensure a correctly signed inverse Hessian matrix. Even a high-end commerical package was tested. However, none of them performed either as accurate (based on Euler Equation errors) or, in some cases (due to many interations), as fast as the approaches we eventually settled upon.

${ }^{17}$ We reject any simulation (and, hence, try another approach) if any of the subproblems fail to solve. Hence, we are forced to use methods that are very stable and perform well globally.
} 
the Euler equation errors produced by the approximation. Appendix $\mathrm{C}$ describes how we calculate the Euler errors for our model as a fraction of consumption at the closest grid point, thereby giving a meaningful (scale independent) interpretation to the errors. Except at corner constraints (where the Euler equation does not hold), the optimizations are required to satisfy a small sup norm error (Appendix C).

\section{Calibration}

Our model is calibrated to the United States economy in 2004. We group individuals by their maximum amount of education obtained: $i \in\{$ "No High School”, "High School”, "College”\}. Specifically, individuals with "No High School” do not have a high school diploma; individuals with "high school” have a high school diploma but not college; individuals with “College” have obtained a college degree.

\subsection{Preferences}

Individual $i$ without a college degree starts working at age 20 while individuals with a college degree begin working at age 22. All households retire at age 65 and can live up to age 100. The mortality data for the whole population follow the National Vital Statistics Reports from National Center for Health Statistics (Elizabeth Arias 2004). The benchmark bequest intensity parameter $b$ is set equal to 5 to help best calibrate the model.

\subsection{Asset Properties}

The riskfree return $R_{f}$ is set equal to $2.00 \%$ while the average equity premium $\mu$ is equal to $4.00 \%$ per year. The standard deviation of the innovation to excess returns $\sigma_{\eta}$ is set to be the historical value $0.157 .{ }^{18}$ When a minimum investment amount in stocks $m$ is required to be positive, it is set equal to $\$ 3000$; this amount is fairly typical for no-load funds which are not connected to an employer-based retirement account. Empirically, the correlation of stocks and individual $i$ 's wages at an annual frequency $\rho_{y \eta}$ is fairly small; we will consider a value of 0.20 as an upper bound. The value of the correlation between the aggregate average wage and stock returns $\rho_{\xi \eta}$, however, is quite large at a low (30-year) frequency, although it

\footnotetext{
${ }^{18}$ This value has been used in a couple previous papers; most of the literature uses a value between $0.15-0.20$.
} 
Table 1: Common Parameters in All Simulations

\begin{tabular}{lr} 
Description & Parameter Value \\
\hline \hline Start working age $\left(t_{0}\right)$ & $20 / 22$ \\
Retirement age $(M)$ & 65 \\
Discount factor $(\beta)$ & see text \\
Coefficient of relative risk aversion $(\gamma)$ & see text \\
Riskless returns $\left(R_{f}\right)$ & 1.02 \\
Mean risky returns $\left(R_{f}+\mu\right)$ & 1.06 \\
Variance of transitory income shocks $\left(\sigma_{\omega}^{2}\right)$ & 0.01 \\
Variance of permanent income shocks $\left(\sigma_{u}^{2}\right)$ & 0.01 \\
Standard deviation of stock returns $\left(\sigma_{\eta}\right)$ & 0.157 \\
Correlation between stock returns and income shocks $\left(\rho_{\xi \eta}\right)$ & see text \\
\hline Social security tax rate $\left(\tau_{S S}\right)$ & 0.124 \\
Investment return tax rate $\left(\tau_{S S}\right)$ & 0.20 \\
Bequest intensity $(b)$ & 5 \\
Minimum investment required in stock account $(m)$ & $\$ 3000$ (when on) \\
Marital status & single \\
Family size & 1
\end{tabular}

is measured with considerable uncertainty. Specifically; a point estimate of 0.80 is consistent with Jermann (1999) and with our own estimates; however, the concomitant 95\% confidence interval is quite large in light of the small number of unique, non-overlapping data points. As a result, we consider a wide range of values for $\rho_{\xi \eta}$, from 0.15 to 0.80 .

\subsection{Labor Income and Housing Expenditures}

Our labor income process follows the careful empirical analysis of Cocco, Gomes and Maenhout (CGM) (2005), who used the Panel Study of Income Dynamics (PSID) to estimate the deterministic function of labor income $g\left(t, F_{i, t}\right)$, which they interpret broadly to include labor income, unemployment compensation, workers compensation, social security, supplemental social security, other welfare, child support, and total transfers from relatives. $g\left(t, F_{i, t}\right)$ is assumed to be additively separable in $t$ and $F_{i, t}$, where age $t$ is estimate as a third-order polynomial estimated to fit the age-wage profiles. They adopt the variances of transitory shocks and permanent shocks on labor income from Carroll (1997). The correlation coefficient between stock returns shocks and labor income shocks follows Campbell 
Table 2: Labor Income Process

\begin{tabular}{lccc} 
Coefficient of characteristic variables for labor income & No high school & High school & College \\
\hline Constant & 2.6275 & 2.7004 & 2.3831 \\
Marital status & 0.4008 & 0.4437 & 0.4831 \\
Family size & -0.0176 & -0.0236 & -0.0228 \\
\hline \hline Coefficient of age dummies for labor income & & & \\
\hline Constant & -2.1361 & -2.1700 & -4.3148 \\
Age & 0.1684 & 0.1682 & 0.3194 \\
Age $^{2} / 10$ & -0.0353 & -0.0323 & -0.0577 \\
Age $^{3} / 100$ & 0.0023 & 0.0020 & 0.0033
\end{tabular}

Table 3: 2004 Progressive Federal Personal Income Tax Rates

\begin{tabular}{cc} 
Tax Rate & Single Filers \\
\hline \hline $10 \%$ & Up to $\$ 7,150$ \\
$15 \%$ & $\$ 7,151-\$ 29,050$ \\
$25 \%$ & $\$ 29,051-\$ 70,350$ \\
$28 \%$ & $\$ 70,351-\$ 146,750$ \\
$33 \%$ & $\$ 146,751-\$ 319,100$ \\
$35 \%$ & $\$ 319,101$ or more
\end{tabular}

et al. (2001). ${ }^{19}$ The share of expenditures spent on housing $h_{t}$ is taken from Gomes and Michaelides (2005), which they estimate using PSID data between 1976 and 1993 as a function of age. Table 1 reports all the parameter values and coefficients. Table 2 illustrates the income process coefficients for different education groups.

\subsection{Progressive Federal Tax and Social Security Benefit Formula}

We adopt the 2004 federal personal income tax rates (shown in Table 3 for single filers). Taxes on both risky and riskless asset returns $\tau_{d}$ are set at proportional rate of $20 \%$.The social security tax rate $\tau_{S S}$ is $12.4 \%$. After calculating the AIYE, we calculate the annual social security benefit using the following three-region "bend point" formula used by the U.S. Social Security system in 2004: 90 percent of the first \$7,344 of AIYE, plus 32 percent of the AIYE over \$7,344 through 44,268, plus 15 percent of the AIYE above 44,268. 
Table 4: Labor Income Process

\begin{tabular}{c||cc}
\multicolumn{1}{c||}{} & No Minimum Investment $m=\$ 0$ & Minimum Investment $m=\$ 3000$ \\
\hline \hline$\rho_{\xi \eta}=0.15$ & (i): $\beta=0.76, \gamma=6$ & (ii): $\beta=0.76, \gamma=6$ \\
$\rho_{\xi \eta}=0.80$ & (iii): $\beta=0.86, \gamma=4$ & (iv): $\beta=0.86, \gamma=4$
\end{tabular}

\section{Results for High School Education}

After obtaining the optimal policy functions for each grid point on the state, we generate an initial distribution of random variables for labor income shocks and portfolio return shocks then simulate over 10,000 households. This section reports the average (mean) outcomes by age for those individuals in the middle education group: those people with a high school degree. We consider for four different calibrations for this education group: (i) a small value of aggregate average wage-stock correlation $\rho_{\xi \eta}$ equal to 0.15 combined with no minimum constraint on investment returns $m=\$ 0$; (ii) again, $\rho_{\xi \eta}=0.15$ but with a minimum constraint on investment returns $m=\$ 3000$; (iii) a larger correlation $\rho_{\xi \eta}=0.80$ with no minimum investment $m=\$ 0$; and (iv) a larger correlation $\rho_{\xi \eta}=0.80$ with a minimum investment $m=\$ 3000$. In each case, the value of risk aversion $\gamma$ and discount rate $\beta$ are chosen to create the closest possible match to the wealth-to-income ratio shown in Figure $2{ }^{20}$ The resulting parameter values are shown for in Table 4.

Figure 3 shows the average labor (plus social security) income and consumption profiles by age for the high school group both pre- and post-retirement for case (i) in Table 4 (the results for the other cases are qualitatitively similar). Average labor income takes the standard "hump shape” $(\cap)$ and drops to zero at retirement when Social Security benefits become positive. Consumption is also hump shaped, which is not standard in a deterministic lifecycle model where consumption should be monotonic in age. Intuitively, in the presence of income uncertainty and CRRA utility (where the third derivative in consumption is positive), individuals save for precautionary reasons in addition to standard retirement reasons. Hump-shaped consumption profiles emerge as a combination of precautionary savings and

\footnotetext{
${ }^{19}$ Since the underlying data was in 1992 dollars while the fiscal policy part of our model is scaled to 2004 dollars, we use the change in the Consumer Price Index 34.11\% as the inflation rate from 1992 to 2004.

${ }^{20} \mathrm{We}$ fix the bequest weight $b=5$ for all simulations to limit the search criterion and since this parameter is the least sensitive.
} 


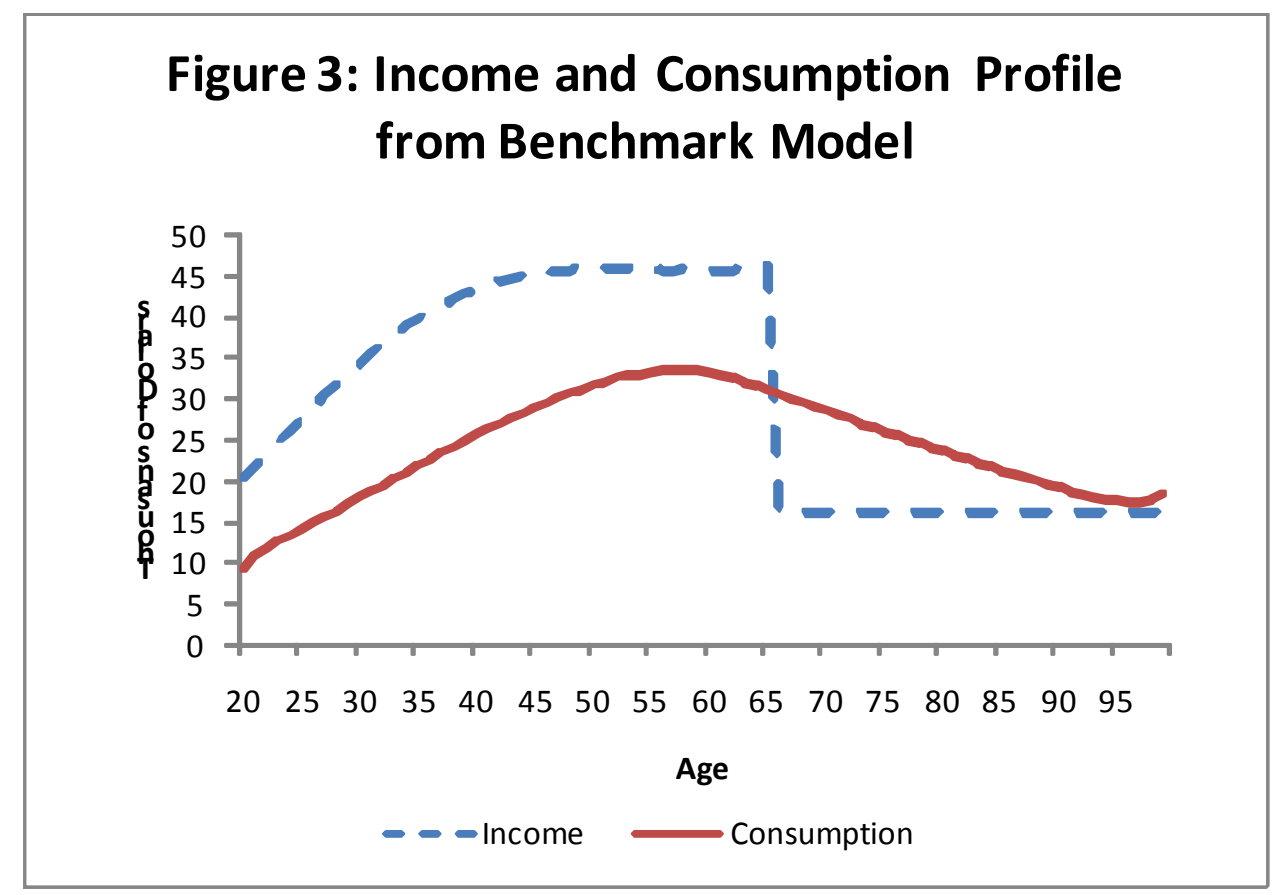

Figure 3:

impatience, producing an optimal consumption path that tracks income (Zeldes 1989; Deaton 1991; Carroll 1992; Hubbard, Skinner and Zeldes 1994).

Figure 4 shows that the model's simulated wealth-income ratios appears to match the data fairly closely for our four different calibrations. One obvious exception is oldest age group where survivor bias might play a role in the data. In particular, according to our simulations, wealthier households will hold a larger portion of the portfolio in equities. Empirically, these households tend to live longer than poorer households. Our simulations, however, do not correct for this wealth-longevity correlation. ${ }^{21}$

Figure 5 shows the share of savings allocated to stocks versus bonds for each of these cases as well as the empirical allocation in the SCF from Figure 1. Notice that the simulated stock allocation is much less than $100 \%$, fair closer to the actual empirical data. This result is in contrast to the traditional lifecycle model where the stock allocation is near $100 \%$ when

\footnotetext{
${ }^{21}$ While allowing for a wealth-longevity correlation would not require an additional state variable, it is actually fairly complicated when $\gamma>1$, due to negative utility. In particular, longer longevity would actually reduce utility. In effect, allowing for longer longevity changes the preference parameters (the augmented utility weight) of an individual, making it difficult to compare.
} 


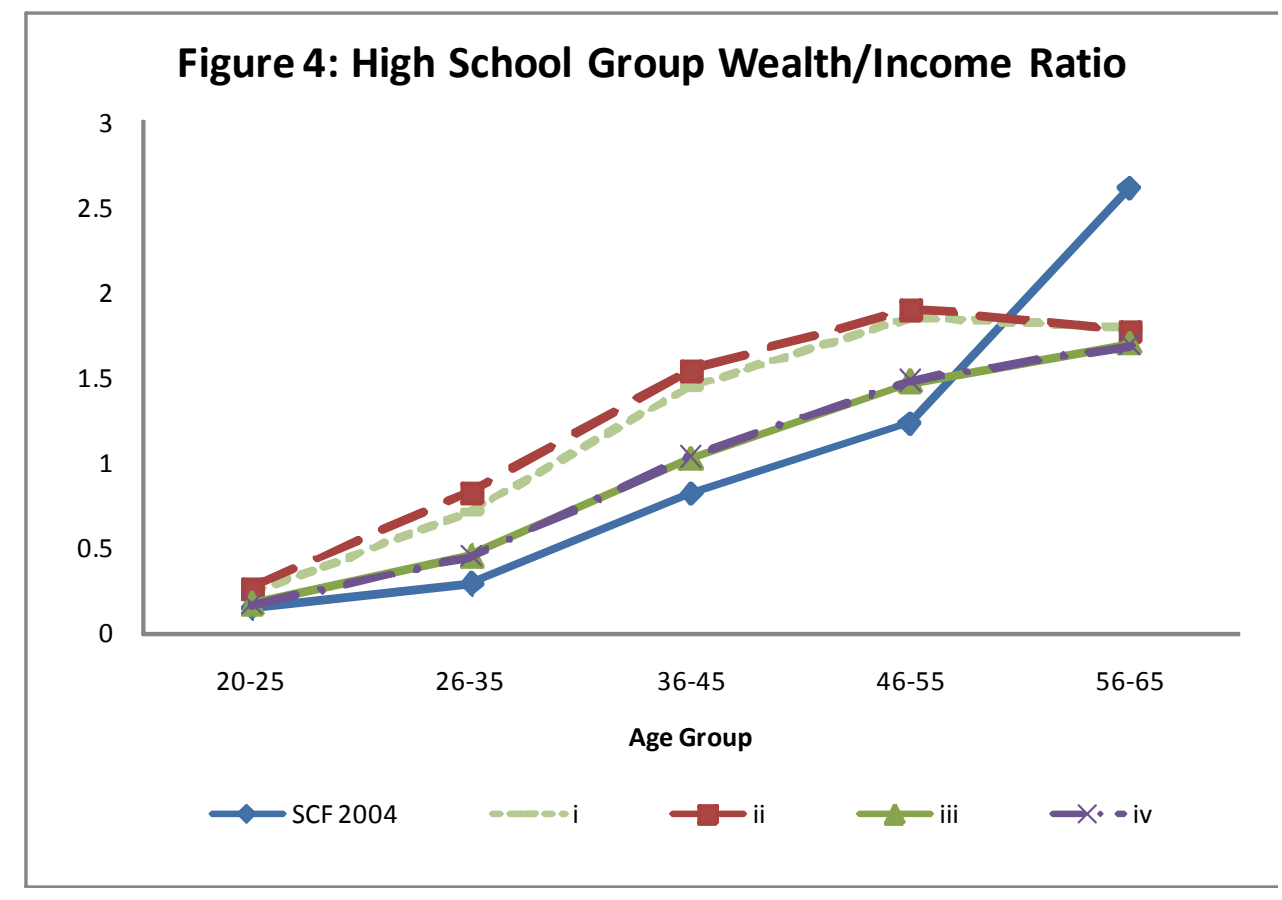

Figure 4:

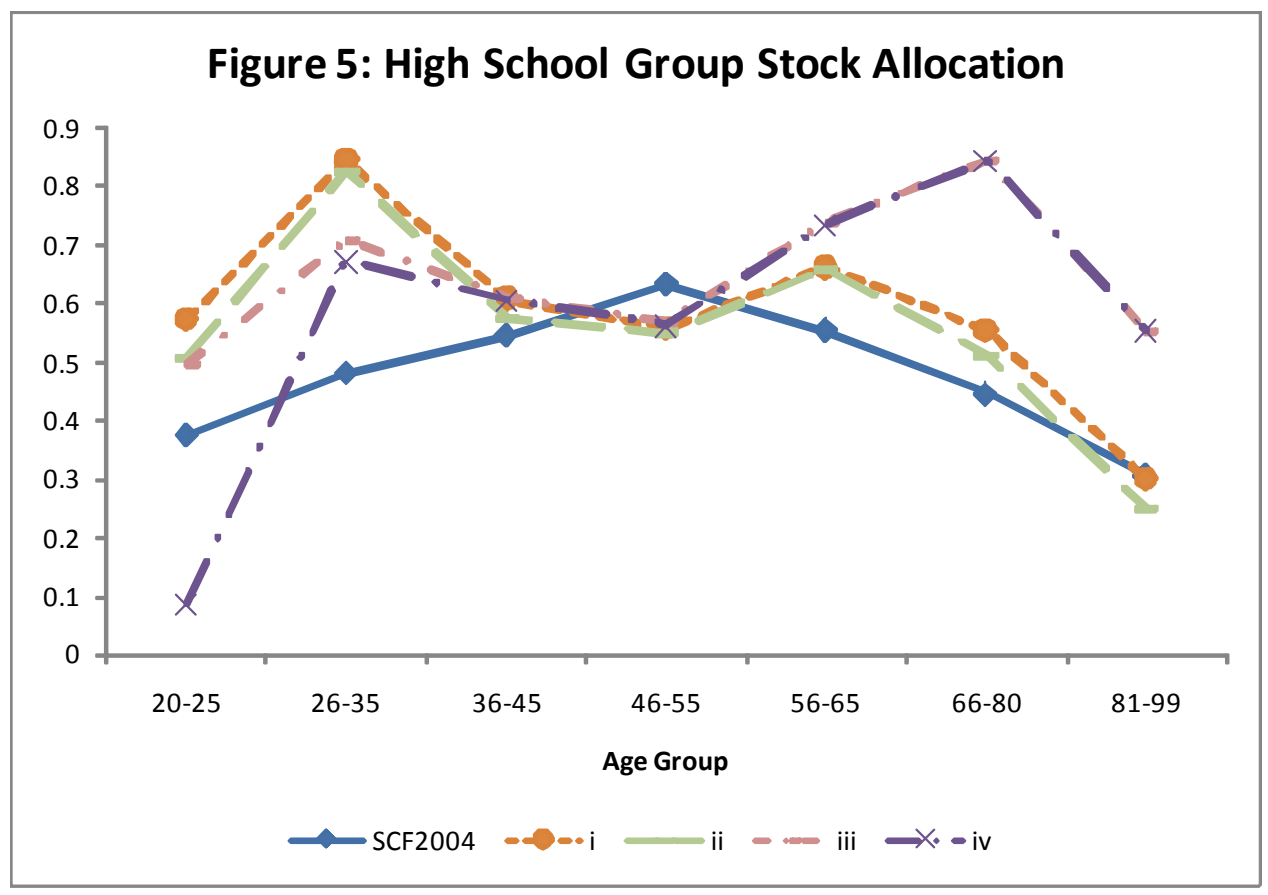

Figure 5: 
young and decreases to about 60\% nearer retirement. Moreover, in each case, the stock allocation profile is fairly reasonable to the "hump shape” $(\cap)$ pattern in empirical data. Of course, the results are not a perfect fit by any means. Our model is clearly stylized and the data itself likely also contains a fair amount of “noise.” Instead, we are more interested in observing general portfolio "patterns" in the presence of realistic wealth-income restrictions.

The hump shape is produced by the model in presence of several competing factors that vary by age. First, risky stocks and social security are highly substitutable at a young age where aggregate wage-indexed social security benefits are still quite uncertain. However, as a person ages, stocks and bonds become substitutable as social security benefits accrue and the potential risk in the wage-indexed factor reduces. The net effect is to cause the allocation in stocks to start relatively small at a young age and then increase in age. Second, similar to previous models, agent $i$ 's specific human capital depreciates over the lifecycle. Since stock returns and individual wages are not highly correlated, this effect produces a larger stock allocation in middle age that then decreases with additional age. Third, the background risk caused by non-insurability of human capital returns interacting with the utility function's Inada condition diminishes over the lifecycle, which can increase the share allocated toward risky stocks. Putting these competing factors together produces a "hump” shaped stock allocation.

In fact, in some cases, a "second hump" (creating a "M" like pattern) also emerges as households approach retirement. This results occurs in cases (iii) and (iv) where a larger amount of weight is placed on future utility. After retirement - that is, once the initial benefit amount is calculated - Social Security benefits are not adjusted for wage growth and only keep pace with inflation. As households approach retirement and more of the Social Security benefit is safe, households with longer horizons (more weight on future utility) will shift their allocation again toward stocks. This result appears to be counterfactual. From a normative perspective, however, they suggest just the opposite advice relative to conventional wisdom: the share of the portfolio devoted to equities should, if anything, increase as people approach retirement when social security benefits become safer. Indeed, the existing empirical evidence might reflect this faulty conventional wisdom. 
Table 5: College Educated

\begin{tabular}{c||cc} 
& No Minimum Investment $m=\$ 0$ & Minimum Investment $m=\$ 3000$ \\
\hline \hline$\rho_{\xi \eta}=0.15$ & (i): $\beta=0.60, \gamma=6$ & (ii): $\beta=0.60, \gamma=6$ \\
$\rho_{\xi \eta}=0.80$ & (iii): $\beta=0.74, \gamma=4$ & (iv): $\beta=0.74, \gamma=4$
\end{tabular}

The plausibility of the needed the underlying parameters varies between the simulations. Table 4 shows that the relatively smaller value of aggregate average wage-stock correlation $\rho_{\xi \eta}=0.15$ (Cases (i) and (ii)) requires $\beta=0.76$ and $\gamma=6$ to properly calibrate with the wealth-income ratio found in the data. In contrast, the relatively larger value of aggregate average wage-stock correlation $\rho_{\xi \eta}=0.80$ (Cases (iii) and (iv)) requires only $\beta=0.86$ and $\gamma=4$ to properly calibrate. These differences imply substantially different tolerances toward risk as well as the discounting of future utility. Together, they suggest that wagedindexed social security can play an important role in creating a plausible model of portfolio choice. Indeed, older households, with more assets at risk, are potentially more sensitive to conventional financial planning advice than younger households, who have fewer assets at risk.

Notice that the presence of the minimum constraint $m$ tends, if anything, to decrease the amount invested in stocks too much. This outcome is especially important under our more plausible parameter cases when $\rho_{\xi \eta}=0.80$. In Cases (iv), with the constraint, the portfolio share in equities at a young age is too low. In Case (iii), without the constraint, however, the portfolio share in equities early in life is very close to the reported empirical value. This result suggests that a minimum account balance is not very important, at least for this education group.

\section{No High School and College}

We also ran the model for the two other education groups: those with "College" and with "No High School." The corresponding calibrating parameters are shown in Tables 5 and 6.

The results for households with college eduction (Figures 6 and 7) are similar except that they tend to hold more equities, at the same age, relative to the middle group considered above who only have a High School diploma. Similarly, on the opposite extreme, households 
Table 6: No High School Education: Parameters

\begin{tabular}{c||cc} 
& No Minimum Investment $m=\$ 0$ & Minimum Investment $m=\$ 3000$ \\
\hline \hline$\rho_{\xi \eta}=0.15$ & (i): $\beta=0.86, \gamma=6$ & (ii): $\beta=0.86, \gamma=6$ \\
$\rho_{\xi \eta}=0.80$ & (iii): $\beta=0.94, \gamma=4$ & (iv): $\beta=0.94, \gamma=4$
\end{tabular}

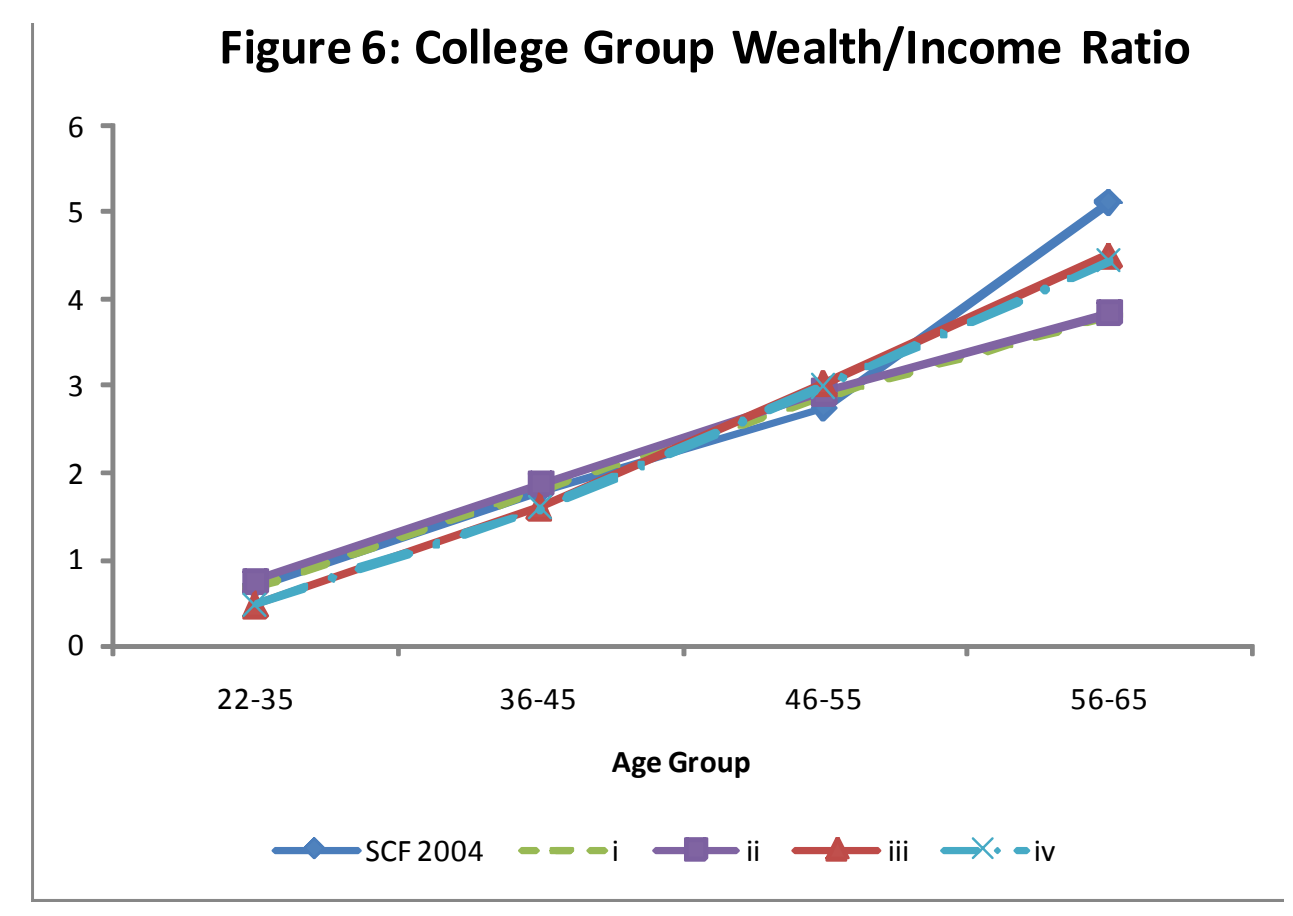

Figure 6:

Without High School (Figures 8 and 9) tend to hold fewer equities, at the same age, relative to the High School group.

These results are generated by the progressive nature of the U.S. Social Security system: the Social Security replacement ratio for poorer households is substantially larger than for richer households. Although future income is stochastic, households still make rational expectations based on the moments of the underlying processes. As a result, Social Security benefits tend to crowd out the savings for younger households that are poorer, which is a conventional result. However, for poor households, Social Security will also crowd out more of the amount of their savings that is devoted to stocks due to the correlation with Social Security at low frequency. As before, the most plausible values of $\beta$ and $\gamma$ occur at a larger value of $\rho_{\xi \eta}$. 


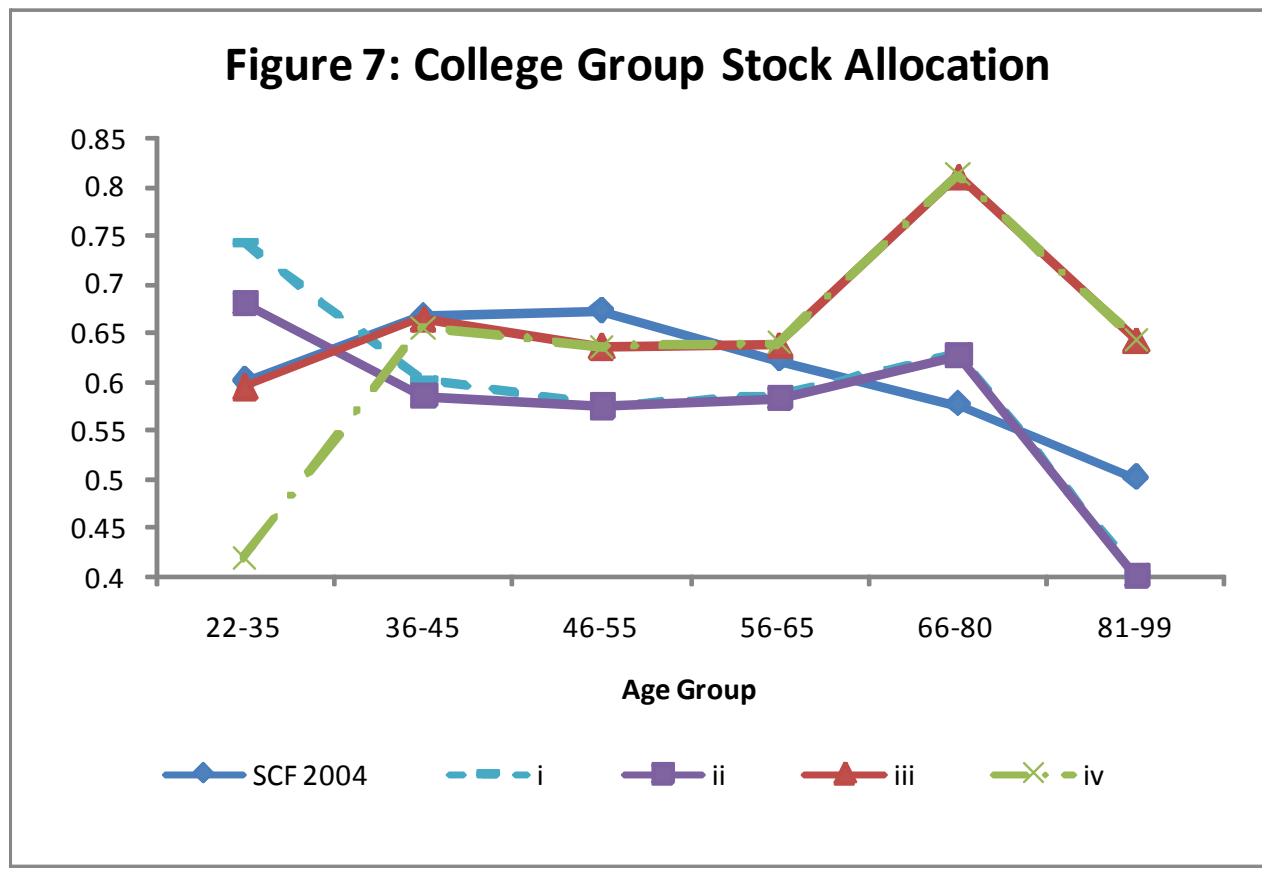

Figure 7:

\section{Without Social Security}

To understand the importance of the role of Social Security, Figure 10 shows the stock allocation when Social Security is completely turned off. The results are shown for two cases: with and without bequests. The results are very similar to those found in previous papers. The stock allocation starts near $100 \%$ for younger households and declines over time. Moreover, in the case without any bequest motive $(b=0)$, the stock allocation produces the " $U$ " shape, which has been shown in previous papers. This shape is produced by the increasing mortality rate near the end of life that effectively reduces the marginal utility of consumption, effectively making a person feel richer. In the presence of a bequest motive, the the " $U$ " shape, while still somewhat present, is somewhat mitigated because the likelihood of making a "bequest consumption" now increases with mortality. 


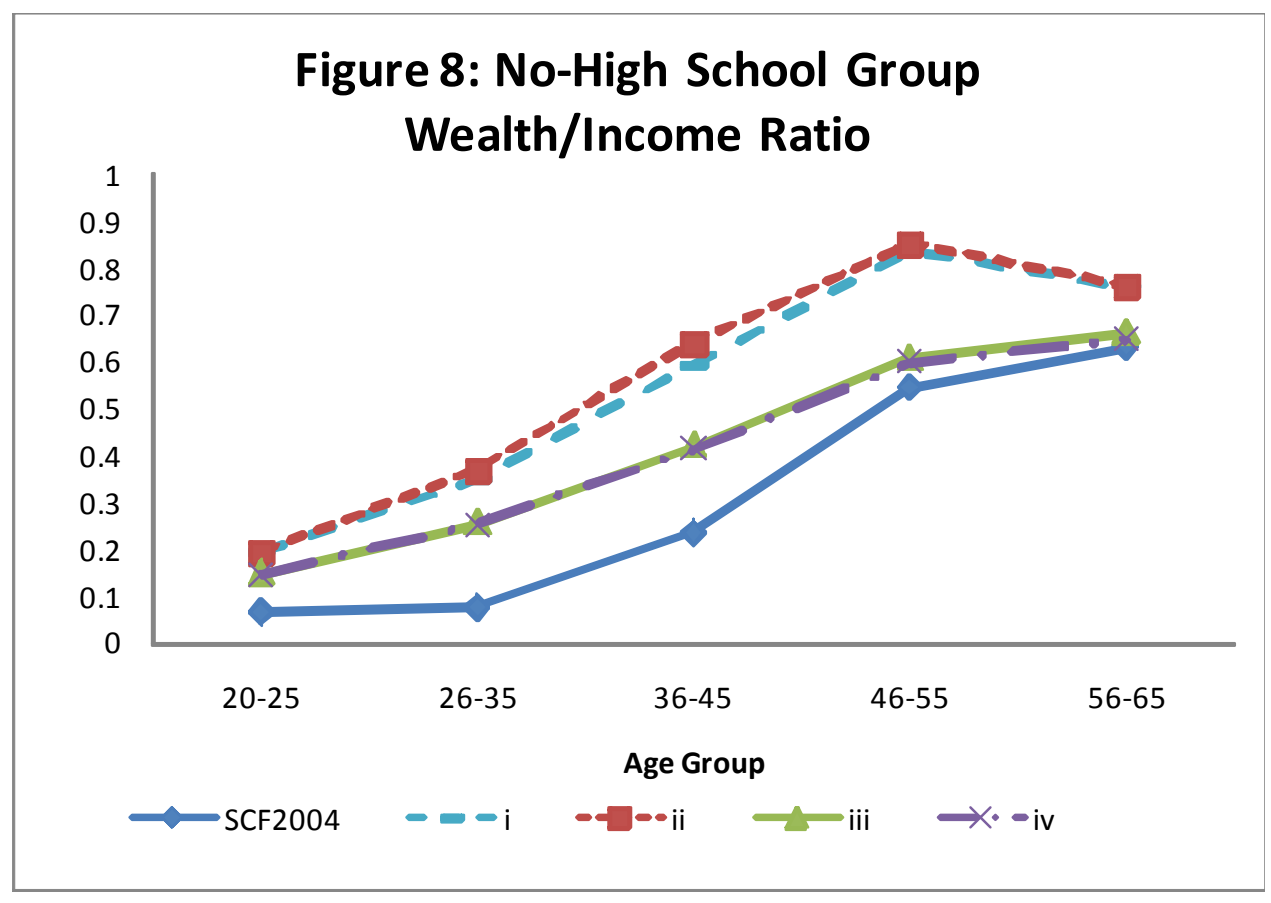

Figure 8:

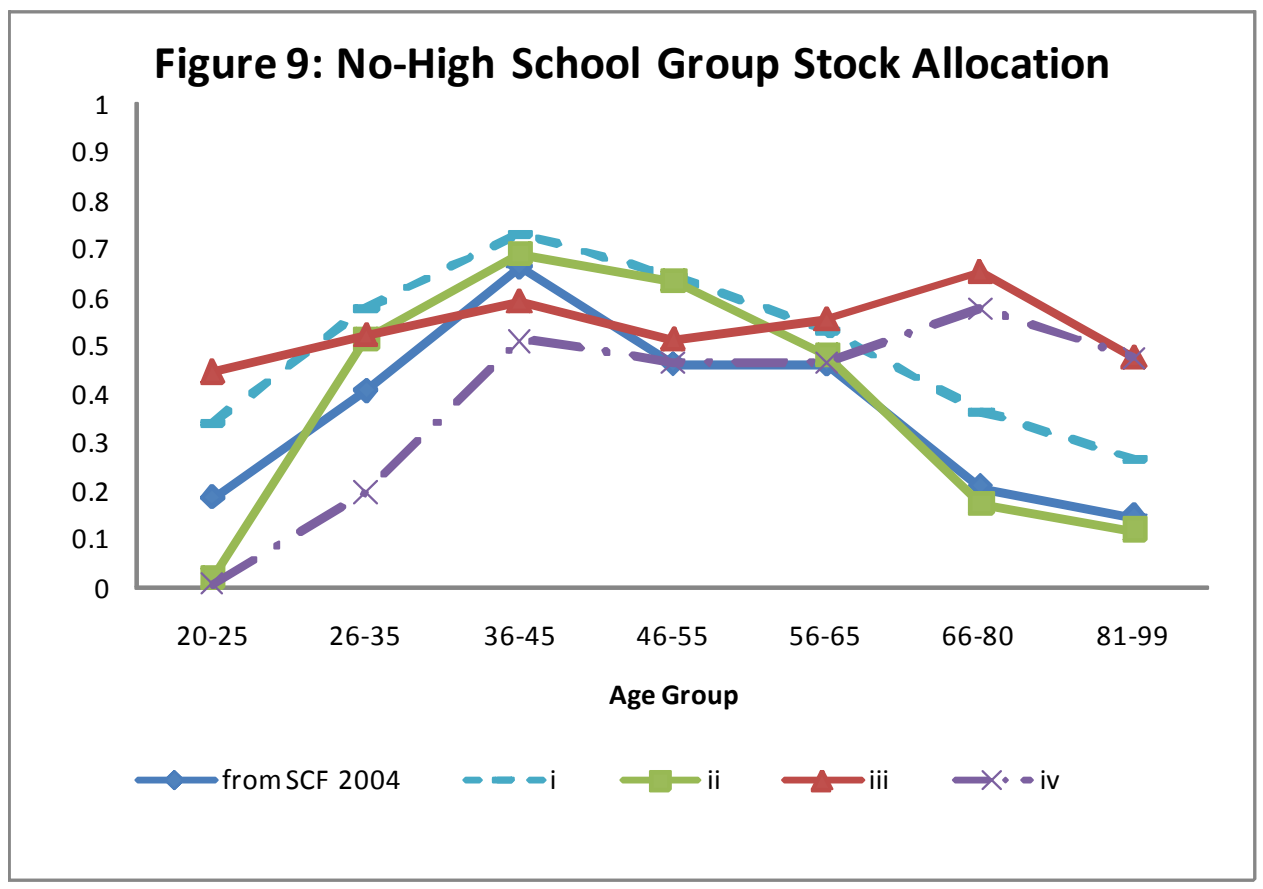

Figure 9: 


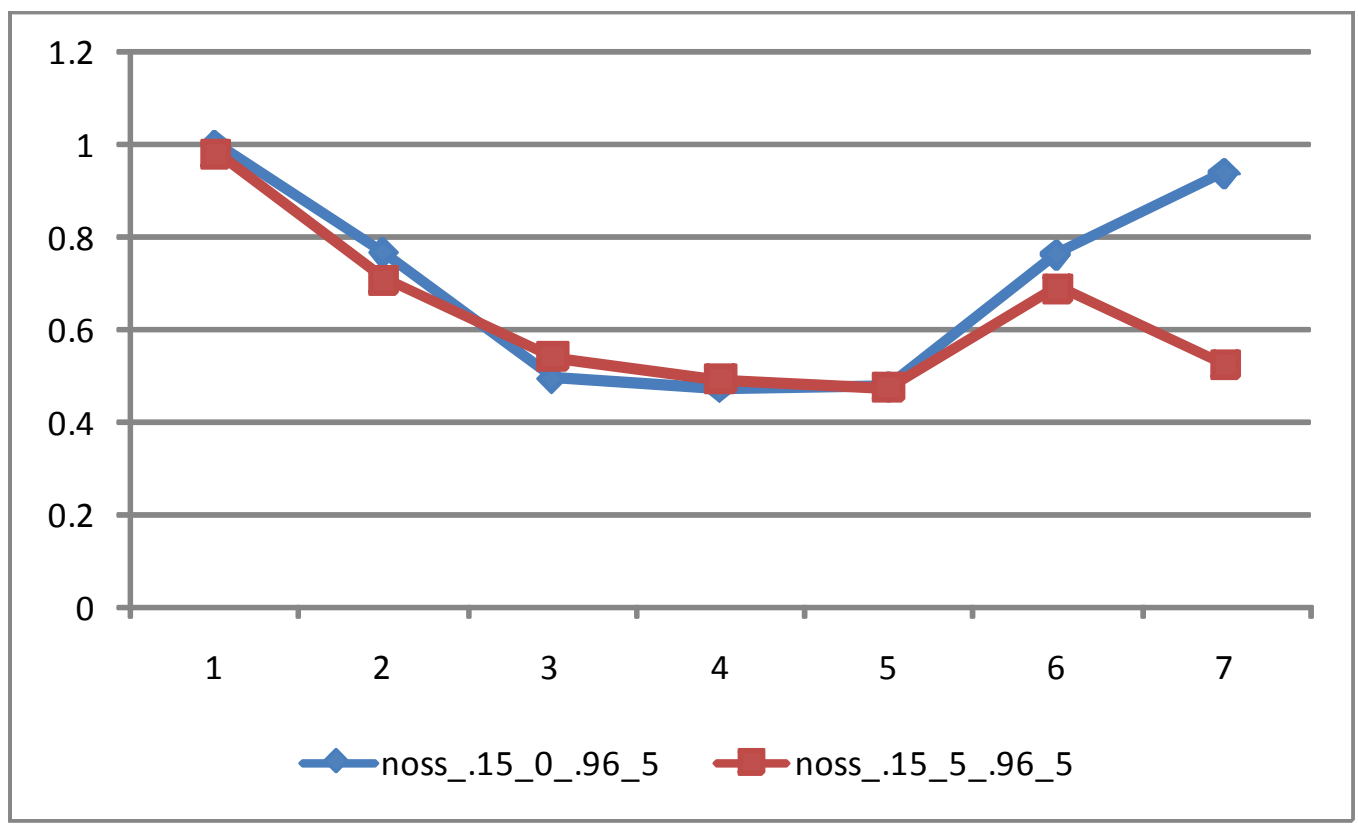

Figure 10:

\section{Target Date Funds}

So-called "target date" (or "lifecycle”) funds have grown enormously during the past five years in the United States. Their main purpose is to essentially simplify the portfolio allocation process along the lines consistent with the traditional lifecycle model, thereby reducing "mistakes." The Pension Protection Act of 2006 increased the popularity of target date funds by allowing employers to make them the "default option" in their 401(k) plans. Of the 380 target-date funds currently in existence, more than 300 are less than five years old. ${ }^{22}$

Of course, relative to our model, any lifecycle allocation rule would, by definition, produce a lower level of welfare than the age-based allocation produced by our model itself. So, we instead ask a more meaningful question: do target date funds actually produce a higher level of welfare relative to what households were achieving on their own before they these funds were introduced? In particular, do target date funds potentially introduce more mistakes than they supposedly cure?

Figure 11 shows the age-indexed stock allocation corresponding to a standard target date

\footnotetext{
${ }^{22}$ http://money.cnn.com/2009/04/27/news/companies/kimes_targetfunds.fortune/index.htm?postversion=2009042713
} 


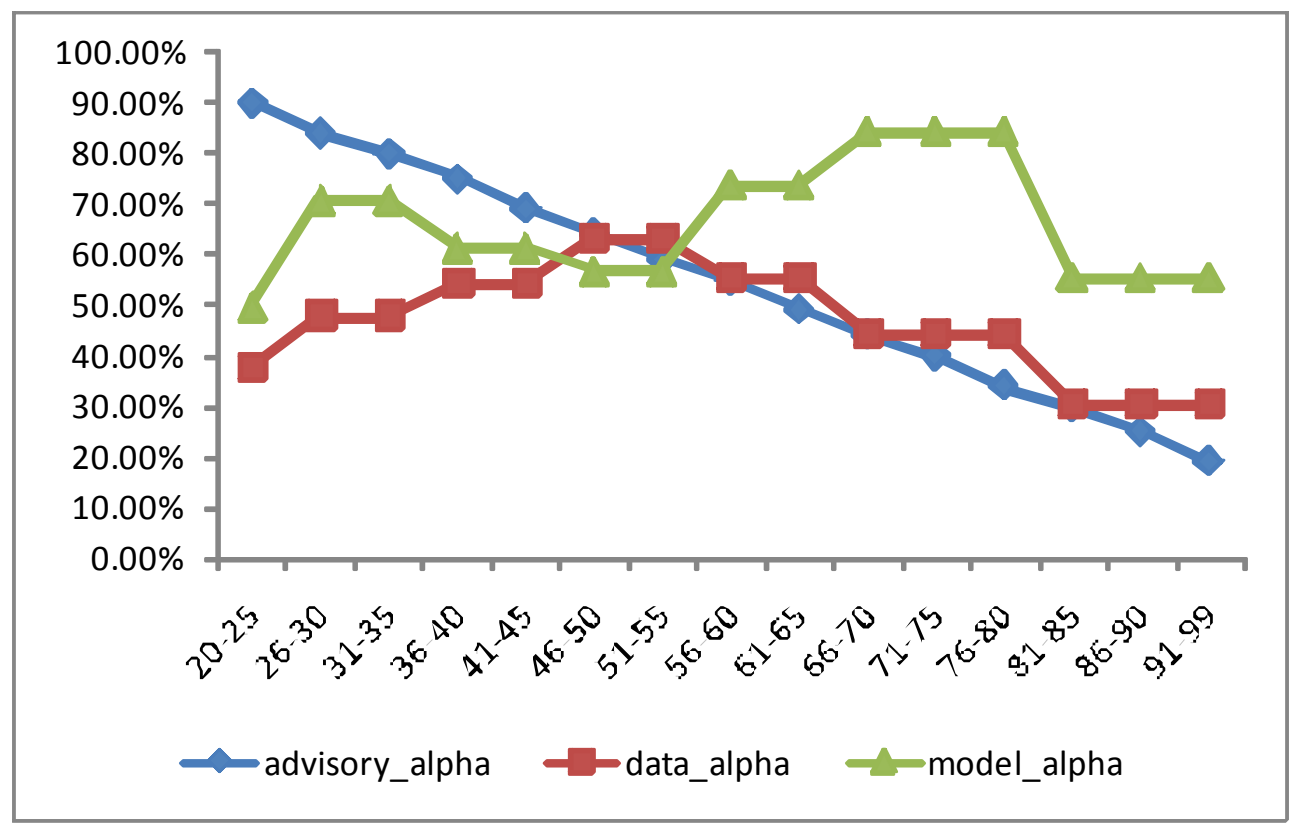

Figure 11:

fund ("advisory alpha"), which starts at $90 \%$ and declines over to about $20 \%$ at age 99 . This allocation is informally recommended by the U.S. Securities and Exchange Commission. ${ }^{23}$ It is also very similar to allocations offered by commercial providers. For comparison, Figure 11 also shows the actual empirical allocation for our middle "High School" education class (“data alpha”) from Figure ; the optimal allocation produced by case (iii) our model is repeated ("model alpha”). Notice that above age 55, the target date fund already closely tracks the empirical allocation. As a result, the target date fund provides very little opportunity to increase welfare for older households relative to their existing behavior; indeed, older households with more assets are likely already sensitive to traditional allocation advice that underlies the target date funds. For households younger than age 55, however, notice that the optimal allocation typically falls in-between the target date path and the actual path. This result suggest that the adoption of a target date fund might be welfare decreasing; households are better off with their current allocations.

To formally measure the change in welfare from adopting a target date fund, we solve

\footnotetext{
${ }^{23}$ http://www.sec.gov/investor/pubs/assetallocation.htm
} 
a constrained version of our model where the asset allocation is taken as exogenous. The constrained optimal solution is calculated under the target date fund allocation shown in Figure 11. The constrained optimal solution is also calculated under the SCF-based empirical allocation shown in Figure 11. Let $\Omega=\int_{X} \int_{z} V_{i, 20}\left(X_{i, 20}, z_{i, 20}\right) \mathrm{d} X_{20} \mathrm{~d} z_{20}$ denote the ex-ante expected utility at age 20, across the different sources of uncertainty upon entering age 20. The corresponding compensating variation (welfare change) associated with adopting the

target date fund at age 20 is then defined as $\left[\frac{\Omega^{\text {Advisory }}}{V^{\text {Data }}}\right]^{\frac{1}{1-\gamma}}$, where $\Omega^{\text {Advisory }}\left(\Omega^{\text {Data }}\right)$ is the expected utility from the target date fund (actual empirical) allocation. The compensating variation is negative (at about $-1 \%$ ), indicating a welfare loss from adopting the target date fund.

However, this particular experiment assumes that the portfolio allocation choice must be made before (ex ante) age 20. Instead, suppose households make their lifetime portfolio allocation choice after the uncertainty upon entering age 20 is resolved in order to calculate their so-called "interim” welfare. Now, the corresponding compensating variation is a manifold (i.e., a matrix of values upon discretization). Even then, nearly all of the compensating variation values are negative.

\section{Conclusion}

This paper examined how households should optimally allocate their portfolio choices between stocks and bonds in a lifecycle model where they face uninsurable wage shocks and an uncertain lifetime. We demonstrated that a progressive wage indexed social security system can fundamentally alter the optimal allocation between stocks and bonds over the lifecycle. Nonetheless, our model made numerous simplifying assumptions that could be extended in future work. Probably the most important assumption is that stock returns are normally distributed. Recent work by Barro (2006), using a representative-agent model, examines how demand for risky stocks decline in the presence of rare events. We plan to consider the role of non-normally distributed shocks in a simplified version of the lifecycle model herein. 


\section{References}

[1] Ameriks, John, Zeldes, Stephen P., 2000. How do household portfolio shares vary with age? Unpublished manuscript. Columbia University.

[2] Attanasio, Orazio, (1995), "The Intertemporal Allocation of Consumption: Theory and Evidence,” Carnegie-Rochester Conference Series on Public Policy, 39-89

[3] Balduzzi, Perluigi, and Anthony Lynch, (1997), “The impact of Predictability and Transaction Costs on Portfolio Choice in a Multiperiod Setting," Working Paper, Boston College and New York University

[4] Barro, Robert J. "Rare Disasters and Asset Markets in the Twentieth Century." Quarterly Journal of Economics, vol. 121, no. 3, August 2006, pp. 823-66.

[5] Benzoni, Luca, Pierre Collin-Dufresne, and Goldstein S. Robert (2004), "Portfolio Choice over the Life-Cycle in the presence of 'Trickle Down’ Labor Income,” Working Paper

[6] Bertaut, Carol C. and Michael Haliassos, (1997), "Precautionary Portfolio Behavior from a Life Cycle Perspective,” Journal of Economic Dynamics and Control, 21, 15111542

[7] Bodie, Zvi; Robert C Merton; William F Samuelson. "Labor Supply Flexibility and Portfolio Choice in a Life Cycle Model.” Journal of Economic Dynamics and Control, vol. 16, no. 3-4, July-October 1992, pp. 427-49

[8] Bodie, Z., J. Detemple, S. Otruba and S. Walter (2004). "Optimal ConsumptionPortfolio Choices and Retirement Planning,” Journal of Economic Dynamics and Control, 28.

[9] Brennan, Michael J. and Y. Xia, (1998), “Resolution of a Financial Puzzle,” Working Paper, Anderson Graduate School of Management, UCLA

[10] Brown, D.P. (1990). “Age clienteles induced by liquidity constraints.” International Economic Review 31, 891-911.

[11] Campbell, John Y., Joao F. Cocco, Francisco J. Gomes, and Pascal J. Maenhout, (2001), "Investing Retirement Wealth: A Life-Cycle Model”, Risk Aspects of Social Security Reform, University of Chicago Press

[12] Campbell, John Y. and John H. Cochrane, (1999), "By Force of Habit: A ConsumptionBased Explanation of Aggregate Stock Market Behavior," Journal of Political Economy, 107, 205-251

[13] Campbell, John Y. and Luis M. Viceira, (1999), "Consumption and Portfolio Decisions When Expected Returns are Time Varying," Quarterly Journal of Economics, May 1999, 433-496 
[14] Carroll, Christopher. D., (1992), “The Buffer Stock Theory of Saving: Some Macroeconomic Evidence,” Brookings Papers on Economic Activity, 2, 61-135

[15] Carroll, Christopher. D., (1997), "Buffer-Stock Saving and the Life-Cycle/Permanent Income Hypothesis,” Quarterly Journal of Economics, 112, 1-55

[16] Carroll, Christopher. D., (2002), "Portfolio of the rich, in Luigi Guiso, Michael Haliassos, and Tullio Jappelli, eds," Household Portfolios, MIT Press, Cambridge, MA

[17] Carroll, Christopher. D., and A. A. Samwick, (1997), "The Nature of Precautionary Wealth,” Journal of Monetary Economics, 40, 41-71.

[18] Cocco, Joao F., (1998), “Owner-Occupied Housing, Permanent Income, and Portfolio Choice”, working paper, Harvard University

[19] Cocco, Joao F., Francisco J. Gomes, and Pascal J. Maenhout, (1998), “Consumption and Portfolio Choice over the Life Cycle,” The Review of Financial Studies, Vol. 18, No. 2

[20] Davis, S., and W. Paul (2000). “Occupation-Level Income Shocks and Asset Returns: Their Covariance and Implication for Portfolio Choice,” NBER Working Paper 7905.

[21] Deaton, A. (1991), “Saving and Liquidity Constraints,” Econometrica, 59, 1121-1142

[22] Elizabeth Arias, (2004), “United States Life Tables,” National Vital Statistics Reports, Vol. 53, No. 6, November 10, 2004

[23] Faig, M., and P. Shum (2002). "Portfolio Choice in the Presence of Personal Illiquid Projects,” Journal of Finance. 57(1), 303-328.

[24] Gakidis, Haralabos. "Portfolio Choice with Uninsurable Labor Earnings.” Massachusetts Institute of Technology, 1998.

[25] Gomes, Francisco, and Alexander Michaelides, (2005), "Optimal Life-Cycle Asset Allocation: Understanding the Empirical Evidence," The Journal of Finance, April 2005, 869-904

[26] Gourinchas, P.-O., and J. Parker, (2002), “Consumption Over the Life Cycle,” Econometrica, 70, 47-91

[27] Gourinchas, Pierre-Olivier and Jonathan Parker, (1996), "Consumption Over the Life Cycle,” working paper, MIT

[28] Heaton, John and Deborah J. Lucas, (1997), "Market Frictions, Saving Behavior and Portfolio Choice,” Macroeconomic Dynamics, 1, 76-101

[29] Hubbard, Glenn, Jonathan S. Skinner and Stephen Zeldes, (1994), "Precautionary Saving and Social Insurance,” Journal of Political Economy, 103, 360-399 
[30] Jagannathan, R., and N. R. Kocherlakota, (1996), "Why Should Older People Invest Less in Stocks Than Younger People?” Federal Reserve Bank of Minneapolis Quarterly Review, 20, 11-23

[31] Jermann, Urban (1999). "Social Security and Institutions for Intergenerational, Intragenerational and International Risk Sharing: A Comment,” Carnegie-Rochester Conference Series on Public Policy: 205-212

[32] Judd, Kenneth L (1992). "Projection Methods for Solving Aggregate Growth Models.” Journal of Economic Theory, 58: 410-452.

[33] Judd, Kenneth L., (1998), “Numerical Methods in Economics” MIT Press.

[34] Kim, Tong Suk, and Edward Omberg, (1996), "Dynamic Nonmyopic Portfolio Behavior,” Review of Financial Studies, 9, 141-161

[35] Merton, Robert C., (1969), "Lifetime Portfolio Selection under Uncertainty: The Continuous-Time Case,” Review of Economics and Statistics, 51, 247-257

[36] Merton, Robert C., (1971), "Optimum Consumption and Portfolio Rules in a Continuous-Time Model,” Journal of Economic Theory, 3, 373-413

[37] Samuelson, Paul A., (1969), "Lifetime Portfolio Selection by Dynamic Stochastic Programming,” Review of Economics and Statistics, 51, 239-246

[38] Storesletten, Kjetil, Chris I. Telmer, and Amir Yaron, (2000), "Asset Pricing with Idiosyncratic Risk and Overlapping Generations,” Working Paper, Carnegie Mellon University

[39] Viceira, Luis M., (2001), “Optimal Portfolio Choice for Long Horizon Investors with Nontradable Labor Income,” Journal of Finance, 55, 1163-1198

[40] Zeldes, S. P. (1989), "Optimal Consumption with Stochastic Income: Deviations from Certainty Equivalence,” Quarterly Journal of Economics, 104, 275-298 


\section{Appendix A}

To construct the the household income, we include wages and salaries (X5702), practice/business/partnership/farm income (X5704), rent/trusts/royolties (X5714), unemployment or worker's compensation (X5716), child support or alimony (X5718), food stamps and welfare income (X5720) and other income (X5724).

Bonds and stocks are constructed as follows. All the acronym-variables are defined in the SAS program supplied by the SCF, which creates summary variables for SCF. Bonds consist of SAVING and MMA (savings and money market accounts), CDS (cerfiticates of deposit), TFBMUTF (tax free bond mutual funds), GBMUTF (government bond mutual funds), OBMUTF (other bond mutual funds), BOND (state, US government and corporate bonds), SAVBND (saving bonds) and COMUTF (combination and other mutual funds), for which we assume that half is invested to bonds. We also add ANNUIT (annuities) and TRUSTS (trusts), for which we count the full value if the individuals invest all in interest earning assets, while the percentage other than stock allocation if the individuals split the investment. Other bond investment includes bonds in IRA/KEOGH plans, bonds in accounttype retirement plans and FUTPEN (other future pension benefits). We also subtract CCBAL (revolving credit card debt), OTHLOC (unsecured loans and loans secured by pensions) and other debt, which includes loans against pensions (X11027, X11127, X11327, X11427, X11527), loans against life insurance (X4010) and loans against margin loans (X3932).

Stocks are made up of STOCKS (directly held stocks), STMUTF (stock mutual funds), half of COMUTF (combination and other mutual funds), OMUTF (other non-bond mutual funds), PENEQ (thrift amounts invested in stock), ANNUIT (annuities) and TRUSTS (trusts) that are invested in stocks. Other stock investment includes stocks in IRA/KEOGH plans, stocks in account-type retirement plans and FUTPEN (other future pension benefits).

The total financial wealth is defined as the total of bonds, stocks, CHECKING (checking accounts) and CALL (call accounts). 


\section{Appendix B}

$f(\cdot)$ denotes the p.d.f. of the variables. $I, J, K, L$ are the numbers of interpolation nodes for labor income shocks and stock returns shocks $\eta, \xi, \omega, \phi$, respectively. The distributions of the shocks are summarized as,

$$
\begin{aligned}
& \omega \stackrel{d}{\longrightarrow} N\left(\mu_{\omega}, \sigma_{\omega}^{2}\right) \\
& \phi \stackrel{d}{\longrightarrow} N\left(\mu_{\phi}, \sigma_{\phi}^{2}\right) \\
& \left(\begin{array}{l}
\eta \\
\xi
\end{array}\right) \stackrel{d}{\longrightarrow} N\left(\begin{array}{ccc}
\mu_{\eta} & \sigma_{\eta}^{2} & \rho_{\xi \eta} \sigma_{\xi} \sigma_{\eta} \\
\mu_{\xi} & \rho_{\xi \eta} \sigma_{\xi} \sigma_{\eta} & \sigma_{\xi}^{2}
\end{array}\right)
\end{aligned}
$$

For each individual $i$, at any time $t$ and any state point $\left(X_{i, t}, z_{i, t}\right)$, the expectation of the value function can be expressed as follows.

$$
\begin{aligned}
E_{\xi \eta \omega \phi} V_{t}\left(\xi, \eta, \omega, \phi, X_{t}, z_{t}\right) & =\int_{-\infty}^{\infty} \int_{-\infty}^{\infty} \int_{-\infty}^{\infty} \int_{-\infty}^{\infty} V_{t}\left(\xi, \eta, \omega, \phi, X_{t}, z_{t}\right) f(\xi, \eta, \omega, \phi) d \xi d \eta d \omega d \phi \\
& =\int_{-\infty}^{\infty} \int_{-\infty}^{\infty} \int_{-\infty}^{\infty} \int_{-\infty}^{\infty} V_{t}\left(\xi, \eta, \omega, \phi, X_{t}, z_{t}\right) f(\eta \mid \xi) d \eta \cdot f(\xi) d \xi \cdot f(\omega) d \omega \cdot f(\phi) d \phi
\end{aligned}
$$

For the bivariate normal distribution, the conditional distribution for one of the variables, given the value for the other variable, is normally distributed. Therefore,

$$
\eta \mid \xi \stackrel{d}{\longrightarrow} N\left(\mu_{\eta \mid \xi}, \sigma_{\eta \mid \xi}^{2}\right)
$$

where

$$
\begin{aligned}
& \mu_{\eta \mid \xi}=\mu_{\eta}+\frac{\rho_{\xi \eta} \sigma_{\eta}}{\sigma_{\xi}}\left(\xi-\mu_{\xi}\right) \\
& \sigma_{\eta \mid \xi}^{2}=\sigma_{\eta}^{2}\left(1-\rho_{\xi \eta}^{2}\right)
\end{aligned}
$$

Following P.262 of Kenneth Judd, if a normal random variable $X$ is distributed $N\left(\mu, \sigma^{2}\right)$, then the general Gauss-Hermite quadrature rule for expectation of $X$ is as follows, 


$$
E(X)=\pi^{-1 / 2} \sum_{i=1}^{n} w_{i} \cdot\left(\sqrt{2} \sigma x_{i}+\mu\right)
$$

where $w_{i}$ are the Gauss-Hermite quadrature weights, and $x_{i}$ are the quadrature nodes, $i=1,2, \ldots, n$.

So, the functional approximation of Gauss-Hermite quadrature to $\eta$ is

$$
\begin{aligned}
E_{\xi \eta \omega \phi} V_{t}\left(\xi, \eta, \omega, \phi, X_{t}, z_{t}\right) & =\pi^{-\frac{1}{2}} \int_{-\infty}^{\infty} \int_{-\infty}^{\infty} \int_{-\infty}^{\infty} \sum_{i=1}^{I} w_{i, \eta} V_{t}\left(\xi, \sqrt{2} \sigma_{\eta \mid \xi}+\mu_{\eta \mid \xi}, \omega, \phi, X_{t}, z_{t}\right) \\
& =\pi^{-\frac{1}{2}} \int_{-\infty}^{\infty} \int_{-\infty}^{\infty} \int_{-\infty}^{\infty} \sum_{i=1}^{I} w_{i, \eta} V_{t}\left(\xi, \sqrt{2} \sigma_{\eta} \sqrt{1-\rho_{\xi \eta}^{2}} \eta_{i}+\mu_{\eta}+\right. \\
\frac{\rho_{\xi \eta} \sigma_{\eta}}{\sigma_{\xi}} & \left.\left(\xi-\mu_{\xi}\right), \omega, \phi, X_{t}, z_{t}\right) \cdot f(\xi) d \xi \cdot f(\omega) d \omega \cdot f(\phi) d \phi
\end{aligned}
$$

where $w_{i, \eta}$ is the weights, $\eta_{i}$ is the nodes over $[-\infty, \infty]$.The procedure of discretizing $\xi$ is to substitute $\sqrt{2} \sigma_{\xi} \xi_{j}+\mu_{\xi}$ for $\xi$, which yields the following,

$$
\begin{aligned}
& E_{\xi \eta \omega \phi} V_{t}\left(\xi, \eta, \omega, \phi, X_{t}, z_{t}\right) \\
= & \pi^{-1} \int_{-\infty}^{\infty} \int_{-\infty}^{\infty} \sum_{j=1}^{J} \sum_{i=1}^{I} w_{i, \eta} w_{j, \xi} V_{t}\left(\sqrt{2} \sigma_{\eta}\left(\sqrt{1-\rho_{\xi \eta}^{2}} \eta_{j}+\rho_{\xi \eta} \xi_{j}\right)+\mu_{\eta}, \omega, \phi, X_{t}, z_{t}\right) \cdot f(\omega) d \omega \cdot f(\phi) d \phi
\end{aligned}
$$

Again $w_{j, \xi}$ and $\xi_{j}$ are the Gauss-Hermite quadrature weights and nodes, respetively. Proceeding with the integral over $\omega$ and $\phi$,

$$
\begin{gathered}
E_{\xi \eta \omega \phi} V_{t}\left(\xi, \eta, \omega, \phi, X_{t}, z_{t}\right) \\
=\pi^{-2} \sum_{l=1}^{L} \sum_{k=1}^{K} \sum_{j=1}^{J} \sum_{i=1}^{I} w_{i, \eta} w_{j, \xi} w_{k, \omega} w_{l, \phi} \cdot V_{t}\left(\sqrt{2} \sigma_{\eta}\left(\sqrt{1-\rho_{\xi \eta}^{2}} \eta_{j}+\rho_{\xi \eta} \xi_{j}\right)+\mu_{\eta}, \sqrt{2} \sigma_{\omega} \omega_{k}\right. \\
\left.\quad+u_{w}, \sqrt{2} \sigma_{\phi} \phi_{l}+u_{\phi} ; X_{t}, z_{t}\right)
\end{gathered}
$$

This model is expensive to compute. The number of nodes in the dynamic programming tree is $I \times J \times K \times L \times T \times S_{1} \times S_{2} \times S_{3} \times 2$, where $I, J, K, L$ are the nodes for different shocks as described above, $T$ is the maximum age that individual can live up to, $S_{1}, S_{2}$ and $S_{3}$ are the numbers of nodes for three state variables separately. Taking 80 as the total life periods and 5 nodes for each shock, the number of nodes for cash on hand is 60 , while the number of nodes for income and indexed wage is 10, separately. A non-uniform power function is used 
to map grid points into state values (details available from the authors). When the minimum stock investment threshold, $m$, is imposed we have two optimization problems at each state: one with bond investment only, the other with both bonds and stocks. Altogether, there are $I \times J \times K \times L \times T \times S_{1}^{\max } \times S_{2}^{\max } \times S_{3}^{\max } \times 2=600,000,000$ optimization problems. If any single optimization problem fails to converge, the entire program is repeated. 


\section{Appendix C}

Take the first-order condtion of Bellman equation

$V_{i, t}\left(X_{i, t}, z_{i, t}\right)=\max _{C_{i, t}, \alpha_{i, t}}\left\{U\left(C_{i, t}\right)+\beta\left[p_{t} \cdot E_{t} V_{i, t+1}\left(X_{i, t+1}, z_{i, t+1}\right)+b\left(1-p_{t}\right) \cdot E_{t} U\left(W_{i, t+1}\right)\right]\right\}$

Subject to

$$
\begin{aligned}
& X_{i, t+1}=R_{i, t}\left(X_{i, t}-C_{i, t}\right)+\left(1-h_{t+1}\right) Y_{i, t+1}^{d} \\
& X_{i, t}=W_{i, t}+\left(1-h_{t}\right) Y_{i, t}^{d}
\end{aligned}
$$

We have

$$
\begin{aligned}
& \frac{\partial V_{i, t}\left(X_{i, t}, z_{i, t}\right)}{\partial C_{i, t}} \\
= & U \prime\left(C_{i, t}\right)+\beta\left\{p_{t} \cdot E_{t}\left[V_{i, t+1} \prime\left(X_{i, t+1}, z_{i, t+1}\right) \cdot\left(-R_{i, t}\right)\right]+b\left(1-p_{t}\right) \cdot E_{t}\left[U \prime\left(W_{i, t+1}\right) \cdot\left(-R_{i, \text { (\$) (3) }}\right)\right.\right. \\
= & 0
\end{aligned}
$$

Change the equation, we have

$$
U \prime\left(C_{i, t}\right)=\beta\left\{p_{t} \cdot E_{t}\left[V_{i, t+1} \prime\left(X_{i, t+1}, z_{i, t+1}\right) \cdot R_{i, t}\right]+b\left(1-p_{t}\right) \cdot E_{t}\left[U \prime\left(W_{i, t+1}\right) \cdot R_{i, t}\right]\right\}
$$

According to the Envelope Therorem, the partial derivative with respect to $X_{i, t}$ is

$$
\frac{\partial V_{i, t}\left(X_{i, t}, z_{i, t}\right)}{\partial X_{i, t}}=\beta\left\{p_{t} \cdot E_{t}\left[V_{i, t+1} \prime\left(X_{i, t+1}, z_{i, t+1}\right) \cdot R_{i, t}\right]+b\left(1-p_{t}\right) \cdot E_{t}\left[U \prime\left(W_{i, t+1}\right) \cdot R_{i, t}\right]\right\}
$$

The right hand sides of Equations (34) and (35) are equal, which gives us

$$
U^{\prime}\left(C_{i, t}\right)=V_{i, t}\left(X_{i, t}, z_{i, t}\right)
$$

Thus, we rewrite Equation (34) as follows,

$$
U_{\prime}^{\prime}\left(C_{i, t}\right)=\beta p_{t} \cdot E_{t}\left[U \prime\left(C_{i, t+1}\right) \cdot R_{i, t}\right]+\beta b\left(1-p_{t}\right) \cdot E_{t}\left[U \prime\left(W_{i, t+1}\right) \cdot R_{i, t}\right]
$$




$$
C_{i, t}=U \prime^{-1}\left\{\beta p_{t} \cdot E_{t}\left[U \prime\left(C_{i, t+1}\right) \cdot R_{i, t}\right]+\beta b\left(1-p_{t}\right) \cdot E_{t}\left[U \prime\left(W_{i, t+1}\right) \cdot R_{i, t}\right]\right\}
$$

We define the Euler error as

$$
\begin{gathered}
C_{i, t} \cdot(1+\text { error })=U \prime^{-1}\left\{\beta p_{t} \cdot E_{t}\left[U \prime\left(C_{i, t+1}\right) \cdot R_{i, t}\right]+\beta b\left(1-p_{t}\right) \cdot E_{t}\left[U \prime\left(W_{i, t+1}\right) \cdot R_{i, t}\right]\right\} \\
\text { error }=\frac{U \prime^{-1}\left\{\beta p_{t} \cdot E_{t}\left[U \prime\left(C_{i, t+1}\right) \cdot R_{i, t}\right]+\beta b\left(1-p_{t}\right) \cdot E_{t}\left[U \prime\left(W_{i, t+1}\right) \cdot R_{i, t}\right]\right\}-C_{i, t}}{C_{i, t}}
\end{gathered}
$$

We then take a $\log _{10}$ of the error, the acceptable range is around -3 or smaller. 